\title{
The Degradation of Strength under Varying Oxidizing Conditions for Nuclear Graphite
}

Austin C. Matthews, Joshua J. Kane W. David Swank, and William E. Windes

The INL is a

U.S. Department of Energy

National Laboratory

operated by

Battelle Energy Alliance

April 2019
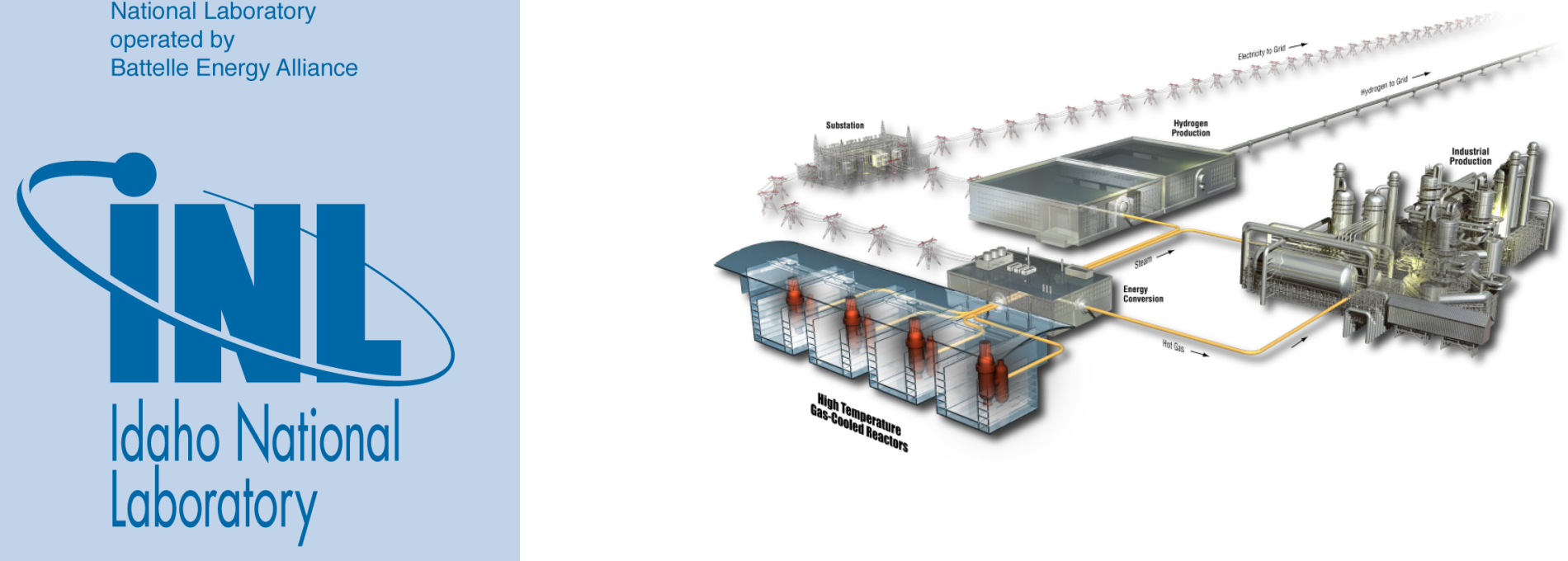


\section{DISCLAIMER}

This information was prepared as an account of work sponsored by an agency of the U.S. Government. Neither the U.S. Government nor any agency thereof, nor any of their employees, makes any warranty, expressed or implied, or assumes any legal liability or responsibility for the accuracy, completeness, or usefulness, of any information, apparatus, product, or process disclosed, or represents that its use would not infringe privately owned rights. References herein to any specific commercial product, process, or service by trade name, trade mark, manufacturer, or otherwise, does not necessarily constitute or imply its endorsement, recommendation, or favoring by the U.S. Government or any agency thereof. The views and opinions of authors expressed herein do not necessarily state or reflect those of the U.S. Government or any agency thereof. 


\title{
The Degradation of Strength under Varying Oxidizing Conditions for Nuclear Graphite
}

\author{
Austin C. Matthews, Joshua J. Kane
}

W. David Swank, and William E. Windes

April 2019

Idaho National Laboratory

INL ART Program

Idaho Falls, Idaho 83415

http://www.inl.gov

Prepared for the

U.S. Department of Energy

Office of Nuclear Energy

Under DOE Idaho Operations Office

Contract DE-AC07-05ID14517 

INL ART Program

\section{The Degradation of Strength under Varying Oxidizing Conditions for Nuclear Graphite}

INL/EXT-19-53723

April 2019

Approved by:

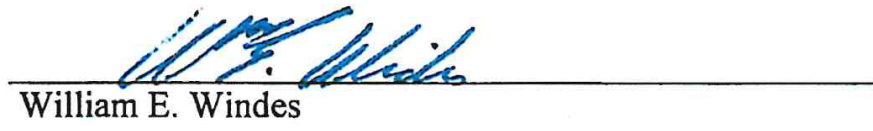

William E. Windes

INL ART Graphite R\&D Technical Lead

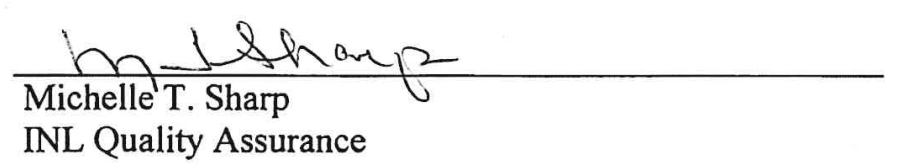

INL Quality Assurance

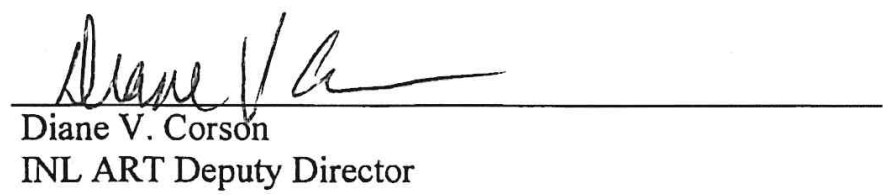

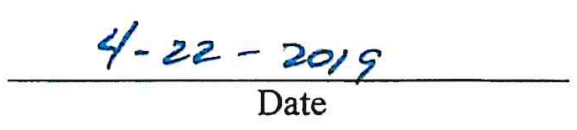
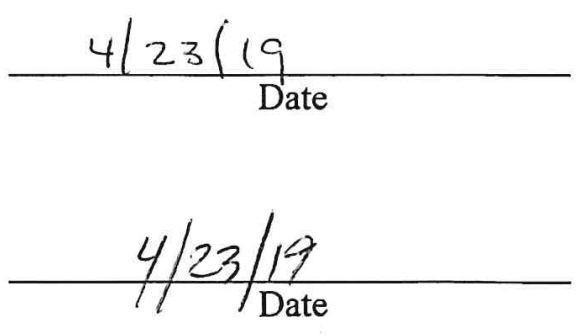



\section{SUMMARY}

Strength behavior of fine- and medium-grain nuclear graphite grades after subjection to varying oxidation conditions are presented. This study provides valuable information for design and eventual licensing considerations for the oxidation behavior of graphite components within a gas-cooled high-temperature reactor and the eventual structural integrity of graphite core components. These tests address the underlying oxidized strength of nuclear-graphite components for oxidized mass losses up to and beyond the current limits recommended for graphite components in the ASME code (maximum mass loss $=10 \%$ ) over a range of oxidation temperatures $\left(550^{\circ} \mathrm{C}-750^{\circ} \mathrm{C}\right)$. Preliminary results generally demonstrate that low-temperature oxidation can result in greater strength reductions than is seen during oxidation at higher temperatures with similar mass-loss levels. Because graphite-component strength is a critical parameter necessary to determine core structural integrity, determining the actual residual strength after oxidation is essential for determining actual component $=$ oxidation limits within the American Society of Mechanical Engineers code. 


\section{CONTENTS}

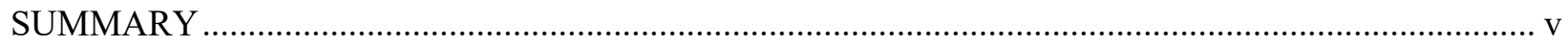

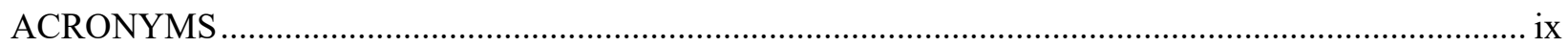

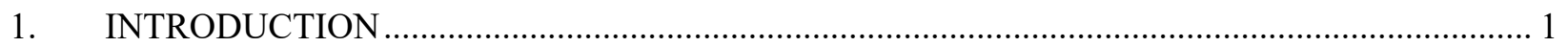

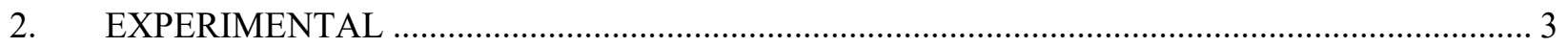

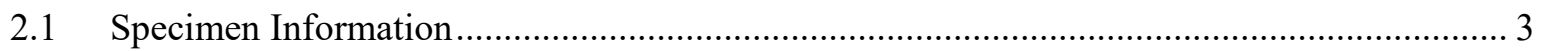

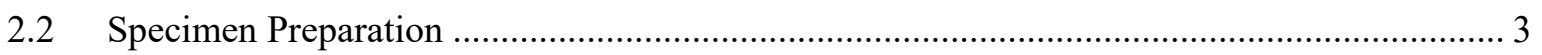

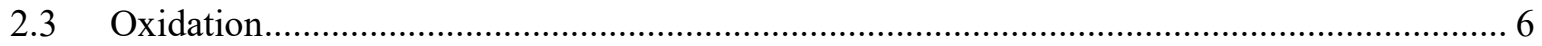

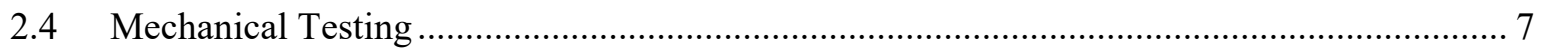

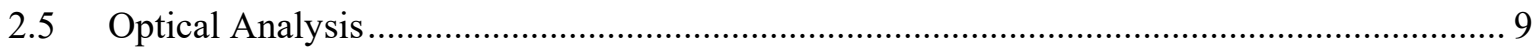

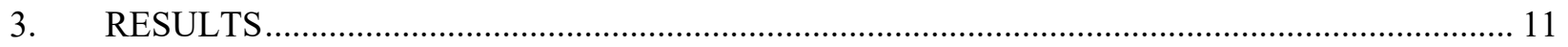

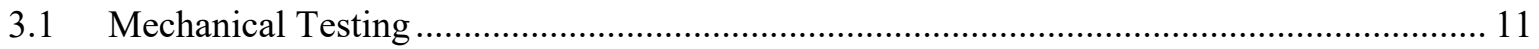

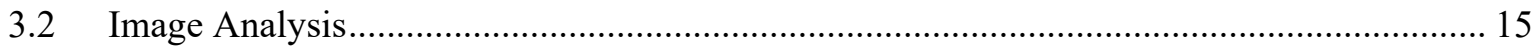

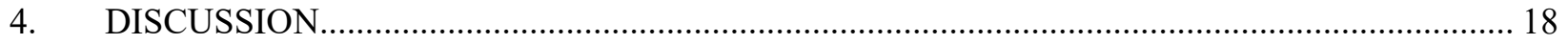

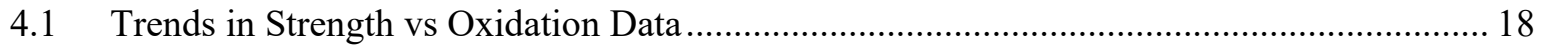

4.1.1 Effects of High- and Low-temperature Oxidation ................................................. 18

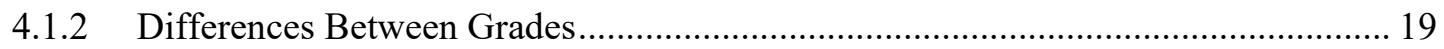

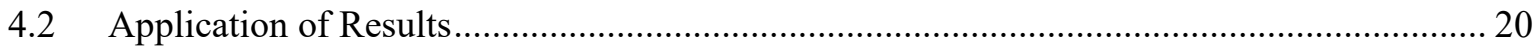

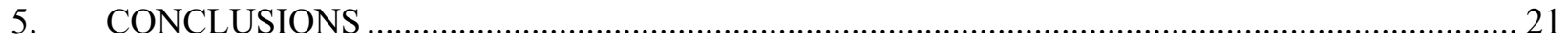

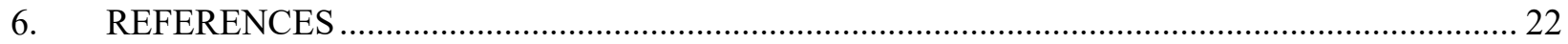

\section{FIGURES}

Figure 1. Apparatus for oxidizing graphite samples..................................................................... 6

Figure 2. Preliminary untrimmed IG-430 samples showing failure at cylinder edges. ............................. 7

Figure 3. Trimmed samples showing failure modes more typical of virgin graphite. ............................... 8

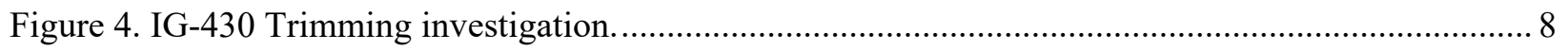

Figure 5. IG-430 untrimmed failure stress comparison. ............................................................. 9

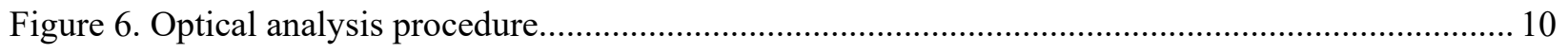

Figure 6. Trimming evaluations for Grade IG-110 (top) and NBG-18 (bottom) at $650^{\circ} \mathrm{C}$. Blue

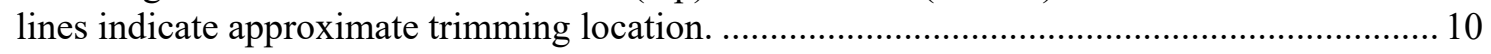

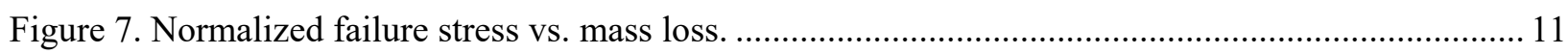

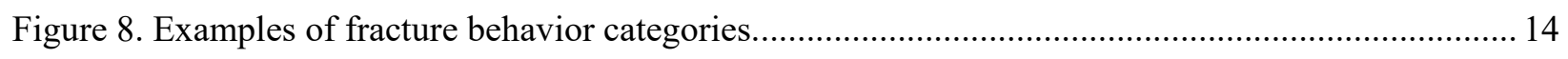

Figure 9. Radial porosity profiles for IG-110 at various temperatures. ................................................. 16

Figure 10. Radial porosity profiles for NBG-18 at various temperatures. ............................................. 17

Figure 11. Characteristic oxygen concentration profiles for graphite at different temperatures.[10]......... 19 


\section{TABLES}

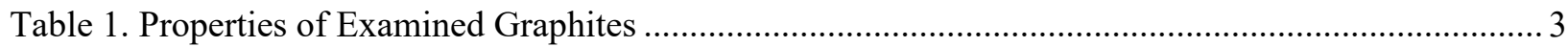

Table 2. Specimen oxidation plan. Numbers represent samples tested for IG-110 and NBG-18

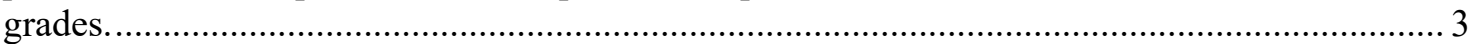

Table 3. Specimen Dimensions for Mechanical Testing ....................................................................... 5

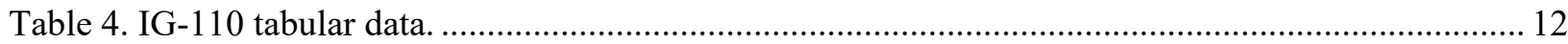

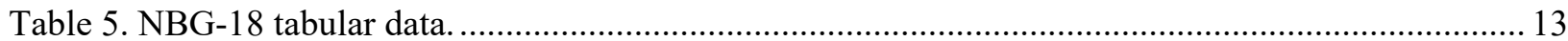




\section{ACRONYMS}

ART Advanced Reactor Technology

ASME American Society of Mechanical Engineers

ASTM American Society of Testing and Materials

BPVC Boiler Pressure Vessel Code

HTR high temperature reactor

INL Idaho National Laboratory

NRC Nuclear Regulatory Commission

PBMR Pebble Bed Modular Reactor

QA quality assurance

$\mathrm{R} \& \mathrm{D} \quad$ research and development

RSA reactive surface area 


\section{The Degradation of Strength under Varying Oxidizing Conditions for Nuclear Graphite}

\section{INTRODUCTION}

The Advanced Reactor Technologies (ART) Graphite Research and Development Program is conducting extensive graphite-oxidation experiments, both chronic and acute, to provide oxidationbehavior data to assist in predicting graphite-component performance in high-temperature reactor (HTR) applications. In past applications, graphite has been used effectively as a structural and moderating material in both research and commercial high-temperature gas-cooled reactor designs.[1,2] Nuclear graphite H-451, used previously in the United States for commercial nuclear reactor graphite components, is no longer available. New nuclear-graphite grades have been developed and are considered suitable candidates for new HTR designs. To support the design and licensing of HTR core components within a commercial reactor, a complete properties database must be developed for these current grades of graphite. Quantitative data on in-service material performance are required for the physical, mechanical, and thermal properties of each graphite grade, with a specific emphasis on data accounting for the oxidation behavior and rates of oxidation to assist in determining the changes to the structural integrity of graphite core components. Further details on the research and development activities and associated rationale required to qualify nuclear-grade graphite for use within an HTR are documented in the graphite-technology research and development plan.[3] This report specifically addresses relatively rapid acute oxidation degradation behavior of nuclear graphite and is directly applicable to American Society of Mechanical Engineers (ASME)-code development activities as well as future HTR license applications requiring this information.

The graphite-moderated HTR design provides a much higher outlet-temperature option than conventional water reactors, making it attractive as a high-temperature heat source for industrial manufacturing processes, hydrogen production, or electricity generation at high efficiency.[4,5,6] While the HTR design is capable of operating safely at these high temperatures $\left(400-1000^{\circ} \mathrm{C}\right.$ outlet) graphite is innately a carbon-based material that can suffer rapid oxidation and subsequent loss of strength when exposed to oxidizing conditions, such as an air-ingress accident. To ascertain the extent of damage to the core integrity for these passively safe, gas-cooled high-temperature designs, the changes in mechanical strength to the graphite must be determined for a variety of oxidizing conditions.

The ASME Boiler Pressure Vessel Code (BPVC.III.5 2017), specifying requirements for using graphite components in nuclear applications, has acknowledged oxidation as a significant degradation issue and has identified that a potential reactor vendor must perform oxidation testing on each specific graphite grade to be used in the reactor core.[7]. Currently, ASME code specifies a maximum 10\% massloss limit for any graphite component. Any component experiencing more than $10 \%$ mass loss is assumed to have zero strength and must be replaced. However, currently (in 2019) there are still unresolved issues surrounding these code requirements that must be clarified - issues such as how the weight loss is calculated (as percentage of core or individual components), whether the mass loss occurs from chronic or acute oxidation, and the actual (rather than assumed) strength loss to large components after a $10 \%$ mass loss. This acute-oxidation study is intended to provide direct data that can address these ASME code questions and to begin providing specific guidance to the ASME code committees, the Nuclear Regulatory Commission, and potential HTR designers.

Unique microstructural features within the specific graphite grades influence the macroscopic oxidation-reaction rate. Simply, the rate is dependent upon relative concentration of active sites $[8,9,10,11,12,13]$ within the graphite and transport efficiency, which is strongly influence by pore morphology and size. Both of these are unique to each graphite grade. $[14,15,16,17]$ These two microstructure-driven features result in grade-specific oxidation rates which have significant potential consequences for determining the degradation potential of graphite core components. Subsection HHA 
for nonmetallic components in the new Section III, Division 5 ASME code (ASME BPVC.III.5) requires any graphite grades used for HTR applications must undergo significant oxidation testing to determine grade-specific oxidation behavior. As a consequence, the licensing of new HTR designs will sustain an interest in graphite oxidation testing of the new graphite grades.

Historically, the rate of graphite oxidation is measurable at temperatures above $400^{\circ} \mathrm{C}$ and increases exponentially with temperature.[18,19,10] As discussed previously, the macroscopic oxidation rates for nuclear-graphite components are dictated by two primary phenomena: the intrinsic chemical kinetics of the reaction of graphite and oxygen (e.g., from either air or water ingress into the inert helium coolant) and transport rates of the reactants to, and products from, reaction sites [10,20]. Generally, both the intrinsic kinetics, $\mathrm{k}$, and the effective diffusivity, $\mathrm{D}_{\text {eff, }}$ are dependent upon temperature according to the following relations:

$$
\begin{aligned}
& k \propto e^{\left(-\frac{1}{T}\right)} \\
& D_{e f f} \propto \mathrm{T}^{\frac{3}{2}}
\end{aligned}
$$

which takes into account the influence of gradients of gaseous oxygen species and the intrinsic reaction rate on the macroscopic oxidation behavior.

The intrinsic oxidation reaction rate depends on the availability of active sites, which are the edges of the graphene sheets where the armchair and zigzag orientations of carbon atoms allow interaction with molecular oxygen to form reactive intermediates. At the crystallite level, this intrinsic oxidation is presumed to be a defining characteristic of the graphite crystal. However, at longer length scales where multiple crystallites reside in patterns of characteristic local orientation with respect to each other, the grade-dependent microstructure also influences local gas diffusion to varying degrees. Similarly, porosity naturally developed in a formed-graphite article depends upon both source feedstock materials and processing.[21,22,23]

An American Society of Testing and Materials (ASTM) standardized test (ASTM D7542) has been developed for testing over the graphite-oxidation temperature range of $500-750^{\circ} \mathrm{C} .[21]$ Testing under the conditions specified by this standard is intended to ensure a controlled oxidation. Controlled oxidation is achieved by providing an abundant and uniform oxidation environment within the controlled temperature regime (i.e., $500-750^{\circ} \mathrm{C}$ ) as described in Section 2, "Experimental." However, the oxidation conditions used for this study follow the intent of the ASTM D7542 standard, and the tests were modified to accommodate multiple specimens oxidizing under the same conditions rather than only one test specimen being oxidized at a time. While this modification allowed for much-faster oxidation testing, it was assumed that specimens were uniformly oxidized because the entire oxidation furnace was oversaturated with filtered air, providing the crucial parameters necessary for a controlled oxidation: abundant reactants (air) and temperatures between $500-750^{\circ} \mathrm{C}$.

Finally, the data and information produced in this report and the referenced documents were generated under the approved ART quality assurance (QA) program in compliance with the appropriate NQA-1 requirements. It is anticipated that all data will be robust enough to stand up to a review by the Nuclear Regulatory Commission as support for a graphite-reactor design selection. 


\section{EXPERIMENTAL}

The graphite grades used for this study, along with the sample description, experimental setup, oxidation environment, and procedures or standards used for testing the specimens are described below. The modifications to the oxidation furnaces were conducted to allow the oxidation-test environments to match controlled conditions as reasonably as possible. Details on the new apparatus to oxidize multiple specimens simultaneously are provided as well.

\subsection{Specimen Information}

Two nuclear-graphite grades with diverse raw materials, fabrication processes, and resulting microstructure were analyzed to assess grade-specific oxidation behavior. Grade IG-110 is a super-finegrain grade, fabricated from petroleum coke using an iso-molding fabrication process. NBG-18 was originally designed and fabricated for the South African Pebble Bed Modular Reactor (PBMR) and is a medium grain grade, fabricated from pitch (coal) coke using a vibrational molding processes. These grades and select nominal properties are listed in Table 1.

Table 1. Properties of Examined Graphites

\begin{tabular}{|c|c|c|c|c|c|c|}
\hline $\mathrm{r}$ & Vendor & $\begin{array}{c}\text { Grain } \\
\text { Designation }\end{array}$ & Grain Size & Coke Type & $\begin{array}{l}\text { Fabrication } \\
\text { Method }\end{array}$ & $\begin{array}{c}\text { Density }^{\mathrm{c}}\left(\mathrm{g} / \mathrm{cm}^{3}\right) \\
\mu \pm \sigma\end{array}$ \\
\hline IG-110 & Toyo Tanso & Super-fine & $20 \mu \mathrm{m}^{\mathrm{b}}$ & Petroleum & Iso-molded & $1.774 \pm 0.002$ \\
\hline NBG-18 & SGL & Medium & $1.6 \mathrm{~mm}^{\mathrm{a}}$ & Pitch & Vibra-molded & $1.852 \pm 0.004$ \\
\hline
\end{tabular}

Due to the grain sizes used for each respective grade, IG-110 has a very fine pore structure while NBG-17 has a much larger pore microstructure. Generally, IG-110 has a much faster $(\sim 3 \times)$ acute oxidation rate than the NBG-18 grade in the kinetically controlled regime. Both grades represent distinctly different fabrication processes, raw materials, and microstructures that will provide a good comparison of oxidation behavior between the available nuclear-graphite grades.

\subsection{Specimen Preparation}

A total of 36 cylindrical samples were prepared from each grade, with dimensions of $25.4 \mathrm{~mm}$ diameter by $50.8 \mathrm{~mm}$ height. Thirty-one samples of each grade were then oxidized according to Table 2 while five specimens from each grade were left unoxidized. After oxidation, the specimens were mechanically tested in compression with the five unoxidized specimens for each grade providing the as-received (as-fabricated) mechanical-strength values. It should be noted that IG-430 was initially included in this sample matrix; however, these samples were mechanically tested without first trimming the oxidation from the ends of the samples, resulting in unexpected and potentially erroneous data that were deemed suspect. Consequently, the IG-430 oxidation and mechanical test results will not be included in this report. However, the erroneous IG-430 testing turned out to be crucial in determining that specimen trimming was necessary; this will be discussed in Section 2.4.

Table 2. Specimen oxidation plan. Numbers represent samples tested for IG-110 and NBG-18 grades.

\begin{tabular}{|c|c|c|c|}
\hline \multirow{2}{*}{$\begin{array}{c}\text { Oxidation } \\
\text { Temperature } \\
\left({ }^{\circ} \mathrm{C}\right)\end{array}$} & \multicolumn{3}{|c|}{ Nominal Mass Loss } \\
\cline { 2 - 4 } & $0 \%$ & $5 \%$ & $10 \%$ \\
\hline 550 & 5 & 5 & 5 \\
\hline 650 & - & 5 & 6 \\
\hline 750 & - & 5 & 5 \\
\hline
\end{tabular}


Not all oxidized specimens were mechanically tested. One sample from each grade from the $650^{\circ} \mathrm{C}$ and $10 \%$ mass-loss testing condition was sectioned in order to perform optical image analysis on the interior microstructure of the specimens. Optical analysis allowed the oxidation-penetration depth to be estimated for each graphite grade. Results from this optical analysis will be discussed in Section 2.5.

The remaining 35 oxidized samples were then machined to remove $3 \mathrm{~mm}$ from both the top and bottom end of each specimen so as to remove the oxidation gradient and make them ready to be mechanically tested by flattening the ends of the samples. The samples were weighed, measured, and compression-tested per ASTM C695, "Standard Test Method for Compressive Strength of Carbon and Graphite." The as-tested weights and dimensional measurements are seen in Table 3. The length values are the average of four evenly spaced measurements, and the diameter values are the average of two sets of measurements taken perpendicular to one another, with three evenly spaced measurements each. The mass loss values were calculated by using the average density of the unoxidized samples of the same grade and the initial machined diameter as follows:

$$
\text { Calculated Mass Loss (\%) }=\left[1-\frac{m}{\rho_{\text {avg }} * h *\left(\frac{25.4}{2}\right)^{2} * \pi}\right] * 100 \%
$$

where $\mathrm{m}$ is the current sample mass, $\mathrm{h}$ is the trimmed sample length, and $\rho_{\text {avg }}$ is the average density of the unoxidized samples of the same grade. 
Table 3. Specimen Dimensions for Mechanical Testing

\begin{tabular}{|c|c|c|c|c|c|c|c|c|c|}
\hline \multirow[b]{2}{*}{$\#$} & \multirow[b]{2}{*}{$\begin{array}{c}\text { Nominal } \\
\text { Oxidation } \\
\text { Temperature } \\
\left({ }^{\circ} \mathrm{C}\right): \\
\end{array}$} & \multicolumn{4}{|c|}{$\begin{array}{l}\text { IG-110 } \\
\text { After Oxidation and Trimming: }\end{array}$} & \multicolumn{4}{|c|}{$\begin{array}{c}\text { NBG-18 } \\
\text { After Oxidation and Trimming: }\end{array}$} \\
\hline & & $\begin{array}{l}\text { Mass } \\
\text { (g): }\end{array}$ & $\begin{array}{l}\text { Avg. } \\
\text { Diameter } \\
(\mathrm{mm}):\end{array}$ & $\begin{array}{l}\text { Avg. } \\
\text { Length } \\
(\mathrm{mm}) \text { : }\end{array}$ & $\begin{array}{c}\text { Calculated } \\
\text { Mass Loss } \\
(\%):\end{array}$ & $\begin{array}{l}\text { Mass } \\
(\mathrm{g}):\end{array}$ & $\begin{array}{l}\text { Avg. } \\
\text { Diameter } \\
(\mathrm{mm}):\end{array}$ & $\begin{array}{l}\text { Avg. } \\
\text { Length } \\
(\mathrm{mm}) \text { : }\end{array}$ & $\begin{array}{c}\text { Calculated } \\
\text { Mass Loss } \\
(\%):\end{array}$ \\
\hline 1 & 550 & 36.209 & 25.10 & 44.62 & $9.7 \%$ & 38.054 & 24.99 & 44.53 & $8.9 \%$ \\
\hline 2 & 550 & 36.125 & 25.12 & 44.54 & $9.7 \%$ & 37.820 & 25.09 & 44.53 & $9.5 \%$ \\
\hline 3 & 550 & 36.234 & 25.07 & 44.70 & $9.8 \%$ & 38.119 & 25.00 & 44.41 & $8.5 \%$ \\
\hline 4 & 550 & 36.394 & 25.08 & 44.57 & $9.1 \%$ & 37.925 & 24.96 & 44.62 & $9.4 \%$ \\
\hline 5 & 550 & 36.457 & 25.21 & 44.65 & $9.2 \%$ & 38.133 & 24.89 & 44.46 & $8.6 \%$ \\
\hline 6 & 750 & 35.970 & 24.85 & 44.31 & $9.7 \%$ & 38.727 & 25.24 & 44.56 & $7.4 \%$ \\
\hline 7 & 750 & 36.697 & 24.85 & 44.40 & $8.0 \%$ & 38.224 & 25.08 & 44.27 & $8.0 \%$ \\
\hline 8 & 750 & 36.150 & 24.83 & 44.76 & $10.1 \%$ & 38.449 & 25.16 & 44.48 & $7.9 \%$ \\
\hline 9 & 750 & 36.354 & 24.92 & 44.49 & $9.1 \%$ & 38.388 & 25.15 & 44.25 & $7.6 \%$ \\
\hline 10 & 750 & 36.615 & 25.01 & 44.24 & $7.9 \%$ & 38.342 & 25.16 & 44.48 & $8.1 \%$ \\
\hline 11 & 650 & 36.303 & 25.27 & 44.47 & $9.2 \%$ & 38.314 & 25.18 & 44.63 & $8.5 \%$ \\
\hline 12 & 650 & 36.262 & 25.25 & 44.55 & $9.4 \%$ & 37.794 & 25.19 & 44.62 & $9.7 \%$ \\
\hline 13 & 650 & 36.089 & 25.29 & 44.26 & $9.3 \%$ & 38.273 & 25.23 & 44.44 & $8.2 \%$ \\
\hline 14 & 650 & 36.098 & 25.27 & 44.65 & $10.0 \%$ & 38.059 & 25.18 & 44.65 & $9.2 \%$ \\
\hline 15 & 650 & 36.291 & 25.31 & 44.33 & $8.9 \%$ & 38.124 & 25.22 & 44.37 & $8.5 \%$ \\
\hline 16 & 750 & 38.365 & 25.20 & 44.56 & $4.2 \%$ & 40.188 & 25.33 & 44.50 & $3.8 \%$ \\
\hline 17 & 750 & 38.378 & 25.20 & 44.34 & $3.7 \%$ & 40.324 & 25.34 & & $3.5 \%$ \\
\hline 18 & 750 & 38.219 & 25.17 & 44.64 & $4.7 \%$ & 40.017 & 25.30 & 44.82 & $4.9 \%$ \\
\hline 19 & 750 & 38.285 & 25.25 & 44.57 & $4.4 \%$ & 40.281 & 25.29 & 44.56 & $3.7 \%$ \\
\hline 20 & 750 & 38.394 & 25.22 & 44.66 & $4.3 \%$ & 40.535 & 25.37 & 44.75 & $3.5 \%$ \\
\hline 21 & 550 & 37.982 & 25.32 & 44.65 & $5.3 \%$ & 40.332 & 25.20 & 44.71 & $3.9 \%$ \\
\hline 22 & 550 & 38.022 & 25.26 & 44.75 & $5.5 \%$ & 39.773 & 25.29 & 44.67 & $5.1 \%$ \\
\hline 23 & 550 & 38.137 & 25.30 & 44.72 & $5.1 \%$ & 40.150 & 25.17 & 44.72 & $4.3 \%$ \\
\hline 24 & 550 & 38.173 & 25.27 & 44.40 & $4.3 \%$ & 39.846 & 25.27 & 44.70 & $5.0 \%$ \\
\hline 25 & 550 & 38.191 & 25.32 & 44.88 & $5.3 \%$ & 39.770 & 25.16 & 44.71 & $5.2 \%$ \\
\hline 26 & 650 & 38.336 & 25.34 & 44.80 & $4.8 \%$ & 40.063 & 25.28 & 44.77 & $4.6 \%$ \\
\hline 27 & 650 & 38.128 & 25.34 & 44.75 & $5.2 \%$ & 39.914 & 25.26 & 44.38 & $4.2 \%$ \\
\hline 28 & 650 & 38.122 & 25.34 & 44.67 & $5.0 \%$ & 40.179 & 25.23 & 44.71 & $4.2 \%$ \\
\hline 29 & 650 & 37.873 & 25.35 & 44.81 & $6.0 \%$ & 39.565 & 25.29 & 44.67 & $5.6 \%$ \\
\hline 30 & 650 & 38.041 & 25.37 & 44.85 & $5.6 \%$ & 40.106 & 25.25 & 44.68 & $4.4 \%$ \\
\hline 31 & Unoxidized & 40.302 & 25.40 & 44.86 & $0.0 \%$ & 42.233 & 25.43 & 44.82 & $0.0 \%$ \\
\hline 32 & Unoxidized & 40.290 & 25.39 & 44.88 & $0.0 \%$ & 42.141 & 25.41 & 44.85 & $0.0 \%$ \\
\hline 33 & Unoxidized & 40.257 & 25.41 & 44.82 & $0.0 \%$ & 42.151 & 25.47 & 44.57 & $0.0 \%$ \\
\hline 34 & Unoxidized & 40.318 & 25.40 & 44.82 & $0.0 \%$ & 42.012 & 25.42 & 44.87 & $0.0 \%$ \\
\hline 35 & Unoxidized & 40.312 & 25.38 & 44.85 & $0.0 \%$ & 42.090 & 25.42 & 44.82 & $0.0 \%$ \\
\hline
\end{tabular}




\subsection{Oxidation}

Specimen oxidation was performed using a custom apparatus built at Idaho National Laboratory. The design is schematically illustrated in Figure 1. The apparatus was designed to create a uniform flow of air over multiple specimens in compliance with ASTM D7542, "Standard Test Method for Air Oxidation of Carbon and Graphite in the Kinetic Regime." Instrument air flows through a porous, sintered quartz frit to provide a uniform plug airflow gas environment over all samples. Samples are held on a quartz "grill," which minimizes surface contact between the frit and the test samples with minimal airflow disturbance. All oxidation was carried out in model BF51894C-1 Linberg/Blue M Moldatherm box furnaces.

Temperatures were measured using a Type $\mathrm{K}$ thermocouple, held $\sim 5 \mathrm{~cm}$ from the graphite samples. Measured specimen temperatures for the 550,650 , and $750^{\circ} \mathrm{C}$ oxidation conditions were 546,659 , and $759^{\circ} \mathrm{C}$, respectively. Air flowed over the samples at a rate of 10 standard liters per minute using an Alicat model MC-10SLPM-DI5M mass-flow controller. The incoming air was heated by flowing through a coil of tubing inside the furnace prior to entering the oxidation apparatus.

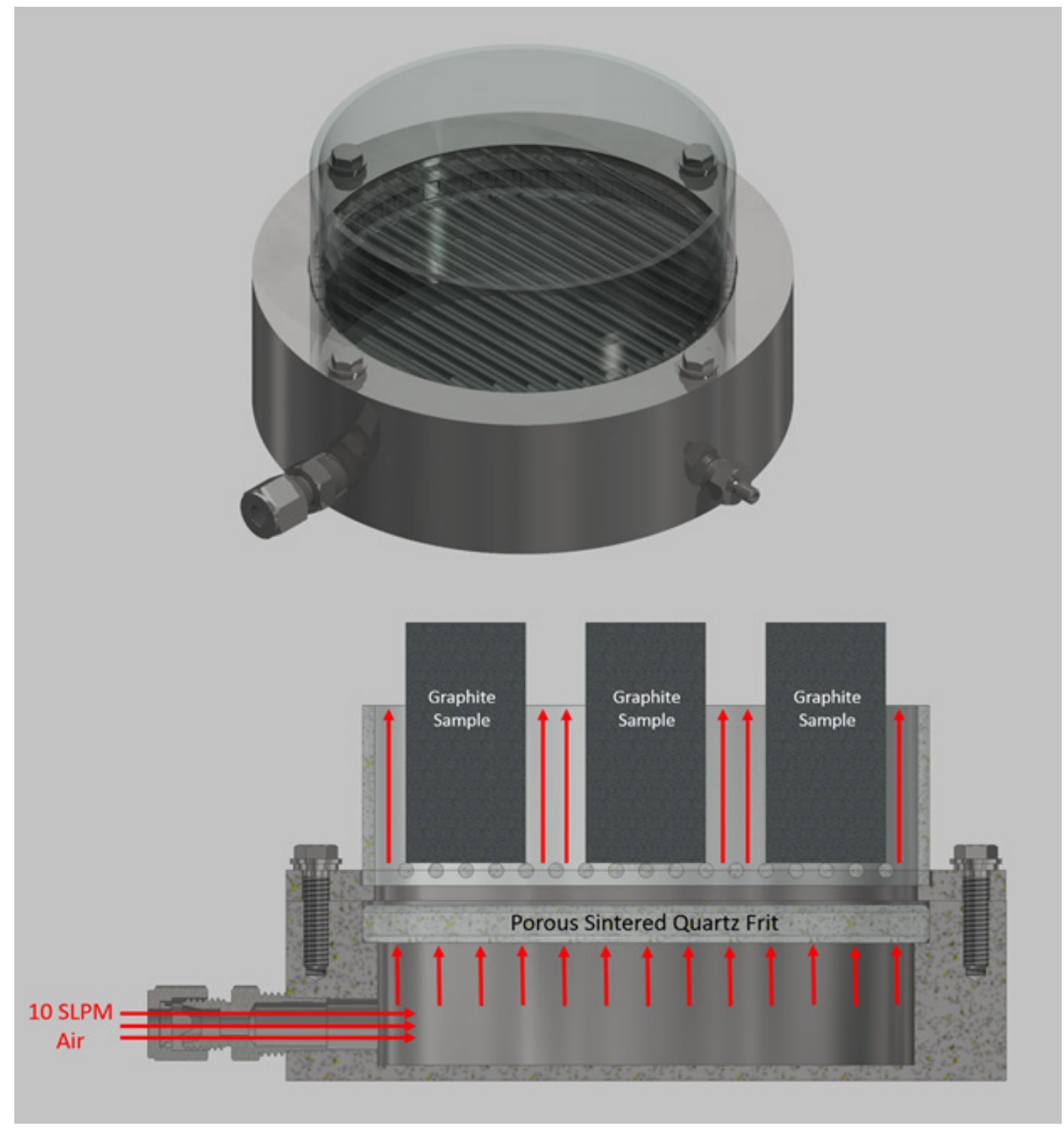

Figure 1. Apparatus for oxidizing graphite samples. 


\subsection{Mechanical Testing}

All mechanical testing was performed at room temperature on an Instron model 5582 electromechanical load frame using an Instron $63209100 \mathrm{kN}$ static load cell. All tests were performed using Instron Bluehill 3 software with a crosshead speed of $1 \mathrm{~mm} / \mathrm{min}$. ASTM test standard C695 was followed as closely as possible, with the following exceptions [24]:

- C695 requires a height-to-diameter ratio between 1.9 and 2.1. Samples had a height-to-diameter ratio between 1.75 and 1.8 after they were trimmed (discussed below).

- $\quad$ C695 requires all surfaces to have a surface finish visually comparable to $0.8 \mu \mathrm{m}$ root mean square or better. Samples met this requirement on the ends of the cylinders after they were trimmed. Faces of the cylinders were left as-oxidized and did not meet this requirement.

Initial mechanical testing after oxidation was performed on grade IG-430 specimens. Initially, the ASTM C695 standard was followed explicitly, with the exception of surface finish, but the specimens demonstrated unexpected failure at the top and bottom edges during loading (Figure 2). These failures along the edges of the cylindrical specimens indicate that the material was failing within the loaded volume directly adjacent to the ends of the specimens, rather than transferring the entire applied stress evenly throughout the specimens as required in ASTM C695. Because the oxidation effects will be most damaging adjacent to the exposed surfaces, this indicated the graphite within this region had been weakened significantly and was failing (i.e., forming and propagating cracks) rather than transferring the applied stress uniformly throughout the specimen volume. The expected failure mode is the generation of multiple fractures along the shear planes inside the specimen, resulting in multiple catastrophic cracks propagating simultaneously yielding a more complete destruction of the sample. Additionally, failurestress values were highly variable and did not show any expected trend. This was believed to be caused by fractures propagating within the region of higher mass loss near the surface on the ends of the samples.
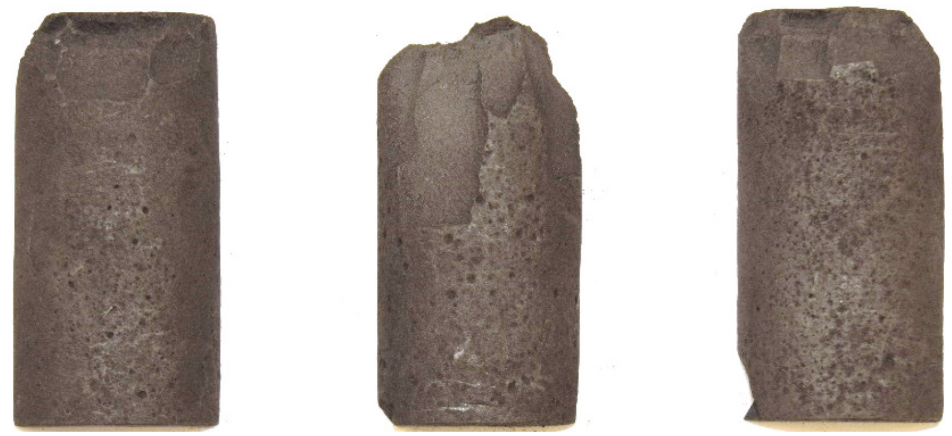

Figure 2. Preliminary untrimmed IG-430 samples showing failure at cylinder edges.

To mitigate the effects of oxidation, a $3 \mathrm{~mm}$-wide section was trimmed from each end of all mechanically tested samples to remove the layer of higher mass loss and leave a perfectly flat surface. This trimming procedure ensured the applied stress was distributed uniformly throughout the specimen interior, rather than propagating cracks within the local volume adjacent the cylinder edges. Sample trimming has been utilized previously with good results.[25] A representation of samples tested after trimming can be seen in Figure 3. These samples show similar failures to unoxidized graphite, thus demonstrating that the applied stress has been distributed throughout the specimen volume. 

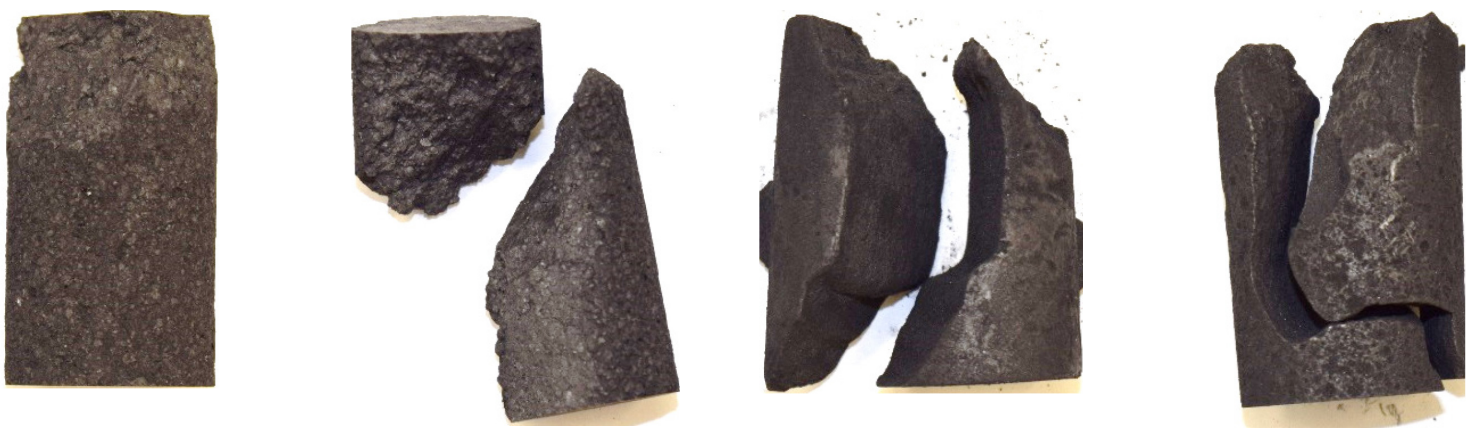

Figure 3. Trimmed samples showing failure modes more typical of virgin graphite.

To verify that this issue was affecting mechanical testing, specimens of IG-430 - both unoxidized and oxidized to $10 \%$ mass loss at $650^{\circ} \mathrm{C}$-were tested against their trimmed counterparts for a preliminary verification of the effectiveness of trimming. The $650^{\circ} \mathrm{C}$ oxidizing condition is assumed to be the worstcase scenario, as discussed in Section 3. It is clear from Figure 4 that the trimmed specimens fail more uniformly than the as-oxidized specimens, and the failure stresses are closer to the expected values.

\section{IG-430 $650^{\circ} \mathrm{C} 10 \%$ Oxidation Stress at Failure}

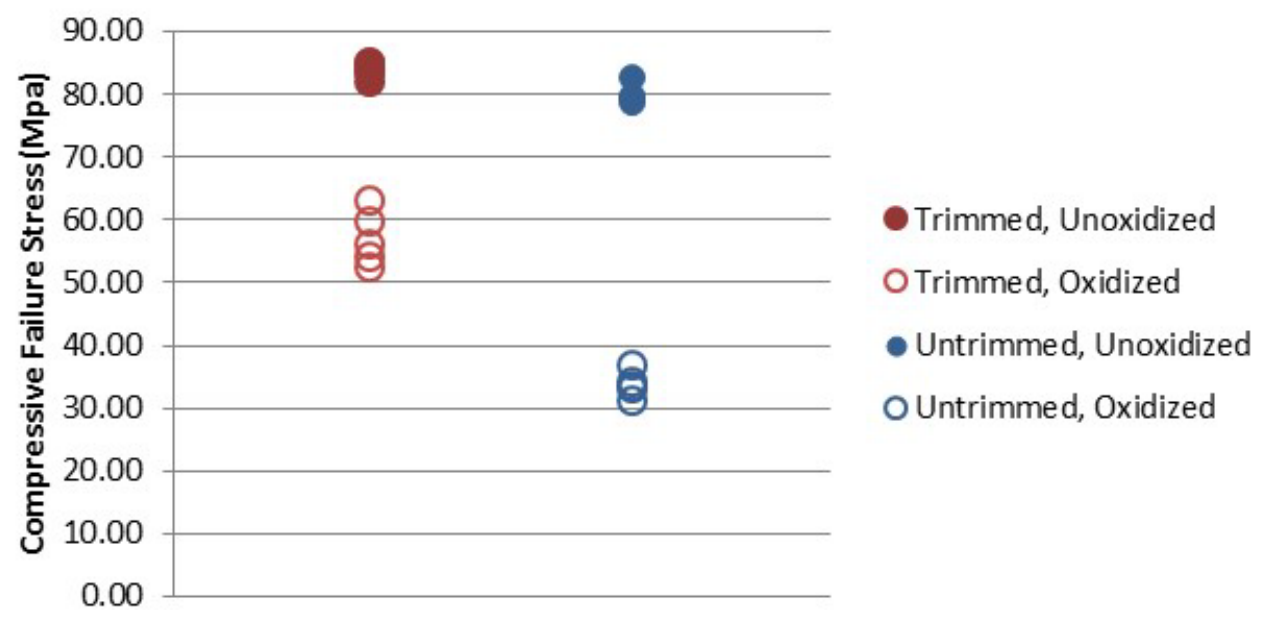

Figure 4. IG-430 Trimming investigation.

Additionally, Figure 5 shows a comparison of the average maximum stress in both trimmed and previously tested specimens. The stress values for the trimmed specimens were normalized as the trimmed, unoxidized specimen stresses were slightly higher than the untrimmed, unoxidized specimens. 


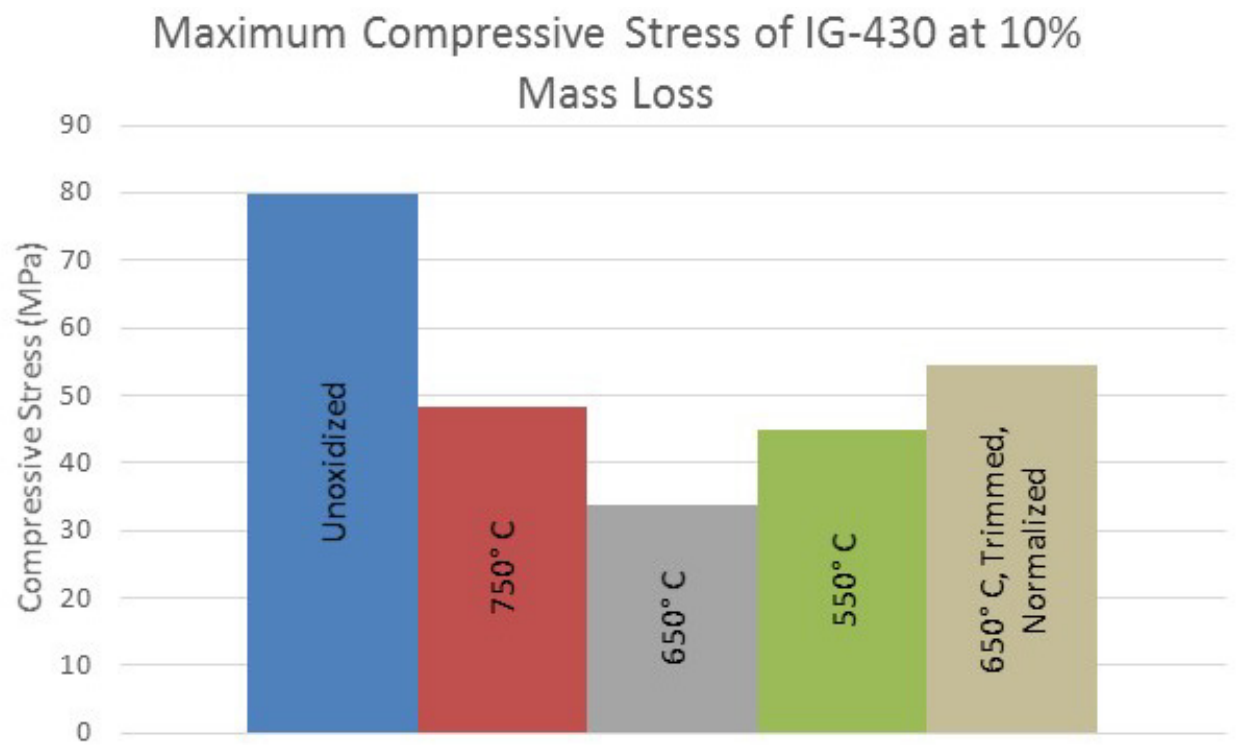

Figure 5. IG-430 untrimmed failure stress comparison.

Unfortunately, a majority of the IG-430 specimens had been mechanically tested before this issue was identified and addressed. As a consequence, the data for IG-430 graphite grade have been excluded from this report, but will be included in a future strength after oxidation study now that the trimming issues has been resolved.

\subsection{Optical Analysis}

Optical analysis was performed to ensure trimming removed the region of highest damage from the ends of the samples and to examine the radial penetration of oxidation into the samples. Samples were sectioned and polished prior to microscopy. The procedure for polishing is as follows, with the samples being cleaned using sonication in water between each step:

- Polishing down to 600 grit on SiC paper

- Polishing with $9 \mu \mathrm{m}$ polycrystalline diamond on a nylon polishing cloth

- Polishing with $3 \mu \mathrm{m}$ polycrystalline diamond on a nylon polishing cloth

- Polishing with $0.05 \mu \mathrm{m}$ alumina on a neoprene polishing cloth.

Composite bright field images were captured with a Keyence VHX-6000 digital microscope. The image analysis consisted of converting the image to greyscale and then to a binary image by an automated, locally adaptive threshold segmentation implemented within the MATLAB image-processing toolbox. This methodology was used as a means of reducing the greyscale image to a binary array, where 1 represents a dark pixel (porosity and background), and 0 indicates a light pixel (graphite). The rows of the image are then summed to estimate how much of the image represents porosity. The vector of row sums is then plotted against the equivalent distance from the end of the sample. This process is illustrated in Figure 6. This method is dependent on image quality and is not an accurate evaluation of total porosity; nevertheless, it is a good representation of the porosity gradient for images collected at identical conditions.

Trimming-depth evaluation analysis was performed on images of the center third of samples to investigate oxidation on the ends of the cylindrical samples and to neglect the oxidation on the cylinder surface. The results are seen in Figure 6, along with the corresponding image. These figures verify the highest porosity region has been removed by trimming the ends by $3 \mathrm{~mm}$. Only the $650^{\circ} \mathrm{C}$ case was 
examined because the lower temperature approaches uniform oxidation, but the higher temperature has a smaller penetration depth.

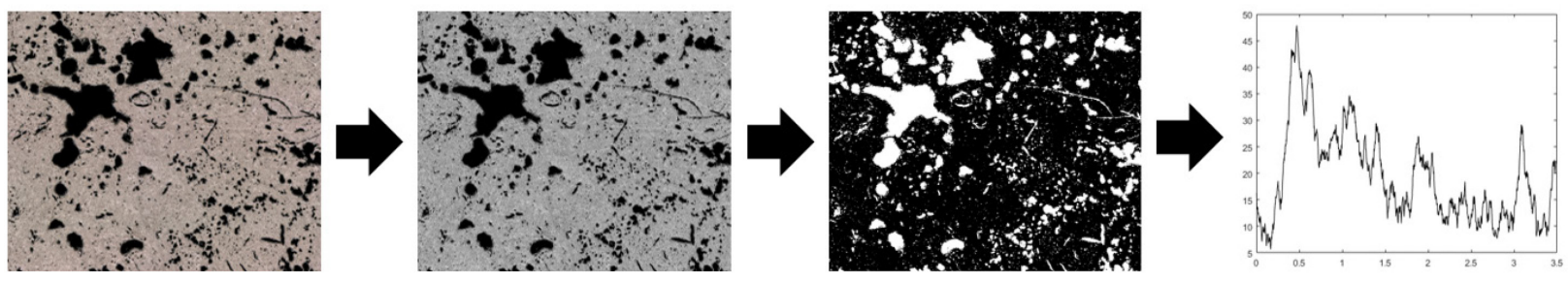

Figure 6. Optical analysis procedure.

Radial penetration-depth evaluation was performed on samples that had been prepared after mechanical testing. Samples were bisected along the axis to reveal a representative cross section. A defect-free portion of each cross section was evaluated and is presented in Section 3.
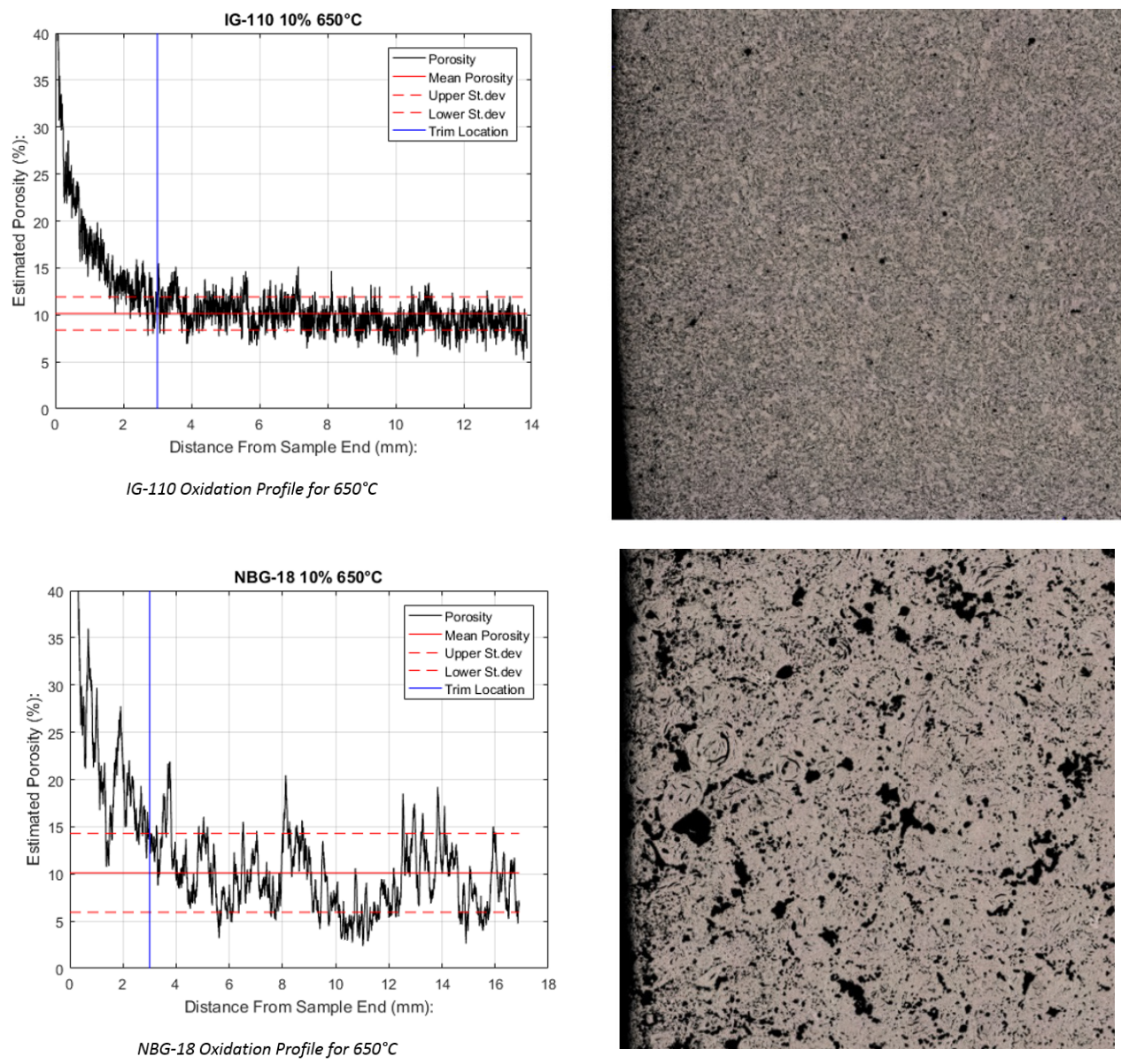

Figure 7. Trimming evaluations for Grade IG-110 (top) and NBG-18 (bottom) at $650^{\circ} \mathrm{C}$. Blue lines indicate approximate trimming location. 


\section{RESULTS}

Oxidation profiles from optical imaging, as well as mechanical test results for both the fine- and medium-grained graphite grades were analyzed for all oxidation conditions. All mechanically tested specimens had both ends trimmed by $3 \mathrm{~mm}$ to remove the majority of oxidation damage from the ends. Mechanical-failure stresses were recorded for all oxidation mass-loss levels for both graphite grades to ascertain the effects of oxidation on the residual strength in fine- and a medium-grained grades.

\subsection{Mechanical Testing}

Failure stress as a fraction of unoxidized failure stress $\left(\sigma_{\text {ox }} / \sigma_{\text {unox }}\right)$ is plotted against oxidized mass-loss percentage for all graphite specimens (Figure 7). Small markers $\left({ }^{\circ},{ }^{\circ}\right)$ represent individual data points while the large markers $(\boldsymbol{\square}, 0)$ are the average value of each subset, with error bars representing \pm 1 standard deviation. Colors correspond to oxidation temperatures $\left(\mathrm{Green}=750^{\circ} \mathrm{C}\right.$, $\mathrm{Red}=650^{\circ} \mathrm{C}$, and Black $\left.=550^{\circ} \mathrm{C}\right)$, and marker shapes correspond to graphite grade $(\cdot=\mathrm{NBG}-18, \circ=\mathrm{IG}-110)$. Lines were included between the corresponding samples of different mass losses solely to guide the readers' eyes.

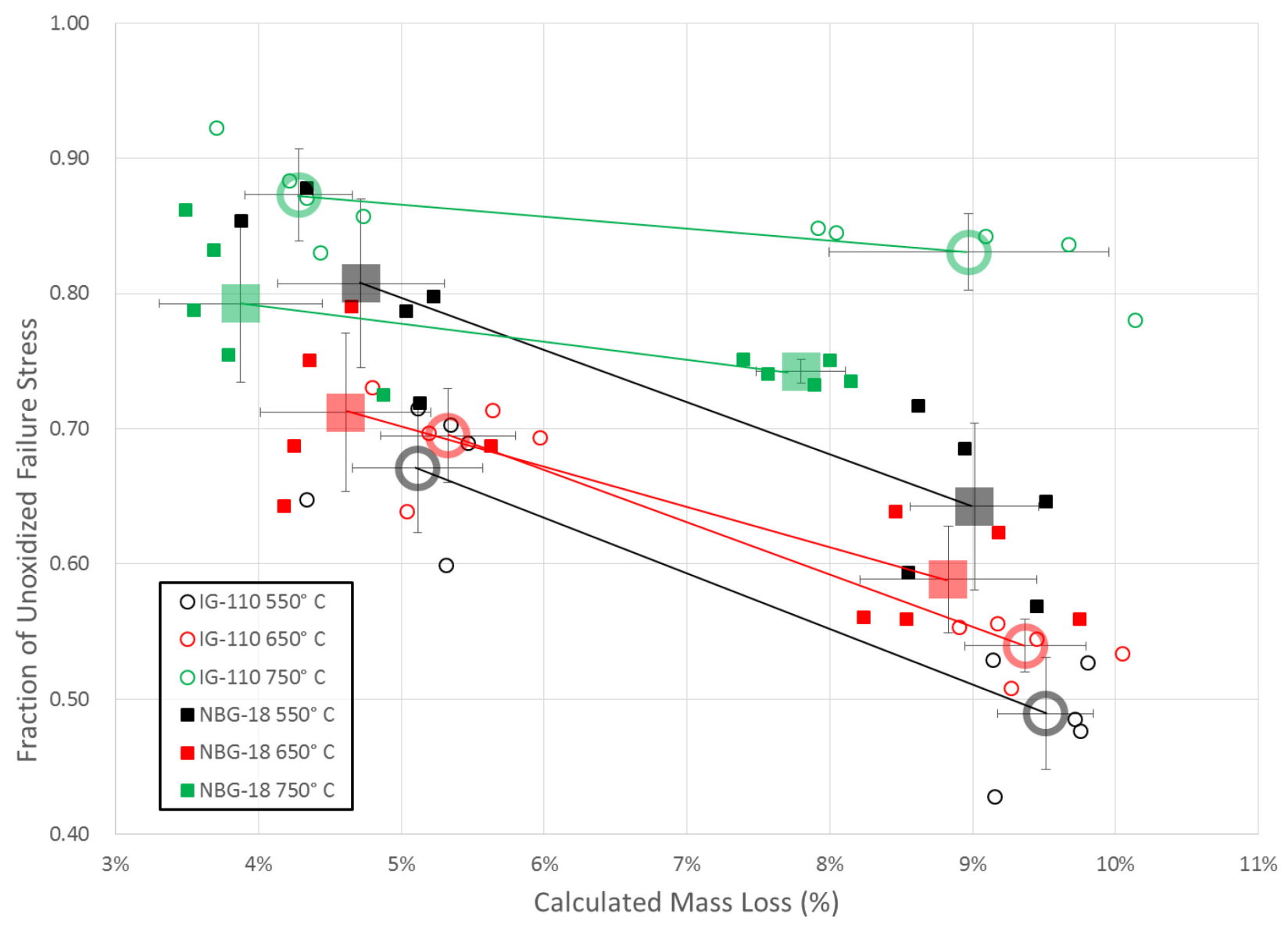

Figure 8. Normalized failure stress vs. mass loss.

Table 4 and Table 5 detail the mechanical test data for IG-110 and NBG-18 grades, respectively. The tables summarize the specimen dimensions, mass, oxidation temperature, and normalized strength at failure for each specimens. Normalized strength values are calculated as:

$$
\text { Normalized Strength }=\frac{\text { Stress at Failure }}{\text { Average Stress at Failure of Unoxidized Samples }}
$$


Table 4. IG-110 tabular data.

\begin{tabular}{|c|c|c|c|c|c|c|c|c|c|}
\hline \multicolumn{10}{|c|}{ IG-110 } \\
\hline $\begin{array}{c}\text { Sample } \\
\text { Number: }\end{array}$ & Mass (g): & $\begin{array}{l}\text { Avg Dia } \\
(\mathrm{mm}):\end{array}$ & $\begin{array}{l}\text { Avg Len } \\
(\mathrm{mm}) \text { : }\end{array}$ & $\begin{array}{c}\text { Actual } \\
\text { Mass Loss } \\
(\%):\end{array}$ & $\begin{array}{c}\text { Stress at } \\
\text { Failure } \\
\text { (Mpa): }\end{array}$ & $\begin{array}{c}\text { Normalized } \\
\text { Strength }\end{array}$ & $\begin{array}{c}\text { Oxidation } \\
\text { Temperature } \\
\left({ }^{\circ} \mathrm{C}\right) \text { : }\end{array}$ & & $\begin{array}{l}\text { Fracture } \\
\text { Category: }\end{array}$ \\
\hline 1 & 36.20919 & 25.10 & 44.62 & $9.71 \%$ & 37.38 & 0.49 & 550 & & 3 \\
\hline 2 & 36.12480 & 25.12 & 44.54 & $9.75 \%$ & 36.70 & 0.48 & 550 & & 3 \\
\hline 3 & 36.23362 & 25.07 & 44.70 & $9.80 \%$ & 40.58 & 0.53 & 550 & & 3 \\
\hline 4 & 36.39360 & 25.08 & 44.57 & $9.14 \%$ & 40.76 & 0.53 & 550 & & 3 \\
\hline 5 & 36.45725 & 25.21 & 44.65 & $9.15 \%$ & 32.97 & 0.43 & 550 & & 3 \\
\hline 6 & 35.96981 & 24.85 & 44.31 & $9.67 \%$ & 64.41 & 0.84 & 750 & & 3 \\
\hline 7 & 36.69654 & 24.85 & 44.40 & $8.04 \%$ & 65.11 & 0.85 & 750 & & 2 \\
\hline 8 & 36.14980 & 24.83 & 44.76 & $10.14 \%$ & 60.11 & 0.78 & 750 & & 3 \\
\hline 9 & 36.35441 & 24.92 & 44.49 & $9.09 \%$ & 64.88 & 0.84 & 750 & & 3 \\
\hline 10 & 36.61497 & 25.01 & 44.24 & $7.92 \%$ & 65.34 & 0.85 & 750 & & 4 \\
\hline 11 & 36.30251 & 25.27 & 44.47 & $9.17 \%$ & 42.83 & 0.56 & 650 & & 2 \\
\hline 12 & 36.26201 & 25.25 & 44.55 & $9.44 \%$ & 41.95 & 0.54 & 650 & & 3 \\
\hline 13 & 36.08937 & 25.29 & 44.26 & $9.27 \%$ & 39.14 & 0.51 & 650 & & 3 \\
\hline 14 & 36.09817 & 25.27 & 44.65 & $10.04 \%$ & 41.10 & 0.53 & 650 & & 3 \\
\hline 15 & 36.29081 & 25.31 & 44.33 & $8.91 \%$ & 42.64 & 0.55 & 650 & & 3 \\
\hline 16 & 38.36530 & 25.20 & 44.56 & $4.21 \%$ & 68.03 & 0.88 & 750 & & 3 \\
\hline 17 & 38.37844 & 25.20 & 44.34 & $3.70 \%$ & 71.05 & 0.92 & 750 & & 2 \\
\hline 18 & 38.21925 & 25.17 & 44.64 & $4.73 \%$ & 66.00 & 0.86 & 750 & & 4 \\
\hline 19 & 38.28531 & 25.25 & 44.57 & $4.43 \%$ & 63.95 & 0.83 & 750 & & 3 \\
\hline 20 & 38.39448 & 25.22 & 44.66 & $4.34 \%$ & 67.05 & 0.87 & 750 & & 4 \\
\hline 21 & 37.98218 & 25.32 & 44.65 & $5.34 \%$ & 54.14 & 0.70 & 550 & & 3 \\
\hline 22 & 38.02163 & 25.26 & 44.75 & $5.47 \%$ & 53.09 & 0.69 & 550 & & 3 \\
\hline 23 & 38.13747 & 25.30 & 44.72 & $5.12 \%$ & 55.08 & 0.72 & 550 & & 3 \\
\hline 24 & 38.17277 & 25.27 & 44.40 & $4.33 \%$ & 49.89 & 0.65 & 550 & & 2 \\
\hline 25 & 38.19061 & 25.32 & 44.88 & $5.31 \%$ & 46.14 & 0.60 & 550 & & 1 \\
\hline 26 & 38.33615 & 25.34 & 44.80 & $4.80 \%$ & 56.26 & 0.73 & 650 & & 2 \\
\hline 27 & 38.12788 & 25.34 & 44.75 & $5.19 \%$ & 53.69 & 0.70 & 650 & & 3 \\
\hline 28 & 38.12170 & 25.34 & 44.67 & $5.04 \%$ & 49.18 & 0.64 & 650 & & 3 \\
\hline 29 & 37.87341 & 25.35 & 44.81 & $5.97 \%$ & 53.43 & 0.69 & 650 & Density & 2 \\
\hline 30 & 38.04106 & 25.37 & 44.85 & $5.64 \%$ & 54.95 & 0.71 & 650 & $\left(\mathrm{~g} / \mathrm{mm}^{3}\right):$ & 3 \\
\hline 31 & 40.30238 & 25.402 & 44.858 & $0.00 \%$ & 77.71 & 1.01 & & 0.0017729 & 3 \\
\hline 32 & 40.28981 & 25.390 & 44.881 & $0.00 \%$ & 76.77 & 1.00 & & 0.0017730 & 3 \\
\hline 33 & 40.25681 & 25.409 & 44.823 & $0.00 \%$ & 75.50 & 0.98 & & 0.0017712 & 2 \\
\hline 34 & 40.31787 & 25.399 & 44.818 & $0.00 \%$ & 77.86 & 1.01 & & 0.0017755 & 3 \\
\hline 35 & 40.31203 & 25.383 & 44.852 & $0.00 \%$ & 77.20 & 1.00 & & 0.0017762 & 2 \\
\hline
\end{tabular}


Table 5. NBG-18 tabular data.

\begin{tabular}{|c|c|c|c|c|c|c|c|c|c|}
\hline \multicolumn{10}{|c|}{ NBG-18 } \\
\hline $\begin{array}{c}\text { Sample } \\
\text { Number: }\end{array}$ & Mass (g): & $\begin{array}{l}\text { Avg Dia } \\
(\mathrm{mm}):\end{array}$ & $\begin{array}{l}\text { Avg Len } \\
(\mathrm{mm}) \text { : }\end{array}$ & $\begin{array}{l}\text { Mass Loss } \\
\text { (\%): }\end{array}$ & $\begin{array}{l}\text { Stress at } \\
\text { Failure } \\
\text { (Mpa): }\end{array}$ & $\begin{array}{l}\text { Normalized } \\
\text { Strength }\end{array}$ & $\begin{array}{c}\text { Oxidation } \\
\text { Temperature } \\
\left({ }^{\circ} \mathrm{C}\right):\end{array}$ & & $\begin{array}{l}\text { Fracture } \\
\text { Category: }\end{array}$ \\
\hline 1 & 38.05414 & 24.99 & 44.53 & $8.94 \%$ & 55.86 & 0.69 & 550 & & 2 \\
\hline 2 & 37.81992 & 25.09 & 44.53 & $9.51 \%$ & 52.71 & 0.65 & 550 & & 1 \\
\hline 3 & 38.11897 & 25.00 & 44.41 & $8.55 \%$ & 48.41 & 0.59 & 550 & & 1 \\
\hline 4 & 37.92538 & 24.96 & 44.62 & $9.45 \%$ & 46.34 & 0.57 & 550 & & 1 \\
\hline 5 & 38.13268 & 24.89 & 44.46 & $8.62 \%$ & 58.46 & 0.72 & 550 & & 1 \\
\hline 6 & 38.72663 & 25.24 & 44.56 & $7.39 \%$ & 61.28 & 0.75 & 750 & & 1 \\
\hline 7 & 38.22369 & 25.08 & 44.27 & $8.00 \%$ & 61.20 & 0.75 & 750 & & 1 \\
\hline 8 & 38.44934 & 25.16 & 44.48 & $7.89 \%$ & 59.70 & 0.73 & 750 & & 1 \\
\hline 9 & 38.38817 & 25.15 & 44.25 & $7.56 \%$ & 60.37 & 0.74 & 750 & & 3 \\
\hline 10 & 38.34240 & 25.16 & 44.48 & $8.15 \%$ & 59.95 & 0.74 & 750 & & 2 \\
\hline 11 & 38.31372 & 25.18 & 44.63 & $8.53 \%$ & 45.58 & 0.56 & 650 & & 2 \\
\hline 12 & 37.79429 & 25.19 & 44.62 & $9.74 \%$ & 45.63 & 0.56 & 650 & & 1 \\
\hline 13 & 38.27334 & 25.23 & 44.44 & $8.23 \%$ & 45.73 & 0.56 & 650 & & 1 \\
\hline 14 & 38.05878 & 25.18 & 44.65 & $9.18 \%$ & 50.84 & 0.62 & 650 & & 2 \\
\hline 15 & 38.12412 & 25.22 & 44.37 & $8.46 \%$ & 52.10 & 0.64 & 650 & & 2 \\
\hline 16 & 40.18804 & 25.33 & 44.50 & $3.78 \%$ & 61.51 & 0.75 & 750 & & 1 \\
\hline 17 & 40.32420 & 25.34 & 44.54 & $3.54 \%$ & 64.25 & 0.79 & 750 & & 1 \\
\hline 18 & 40.01693 & 25.30 & 44.82 & $4.87 \%$ & 59.13 & 0.73 & 750 & & 2 \\
\hline 19 & 40.28097 & 25.29 & 44.56 & $3.69 \%$ & 67.82 & 0.83 & 750 & & 2 \\
\hline 20 & 40.53539 & 25.37 & 44.75 & $3.49 \%$ & 70.28 & 0.86 & 750 & & 2 \\
\hline 21 & 40.33215 & 25.20 & 44.71 & $3.88 \%$ & 69.61 & 0.85 & 550 & & 1 \\
\hline 22 & 39.77287 & 25.29 & 44.67 & $5.12 \%$ & 58.63 & 0.72 & 550 & & 1 \\
\hline 23 & 40.15032 & 25.17 & 44.72 & $4.34 \%$ & 71.60 & 0.88 & 550 & & 2 \\
\hline 24 & 39.84562 & 25.27 & 44.70 & $5.03 \%$ & 64.17 & 0.79 & 550 & & 2 \\
\hline 25 & 39.77012 & 25.16 & 44.71 & $5.22 \%$ & 65.04 & 0.80 & 550 & & 2 \\
\hline 26 & 40.06274 & 25.28 & 44.77 & $4.65 \%$ & 64.46 & 0.79 & 650 & & 2 \\
\hline 27 & 39.91382 & 25.26 & 44.38 & $4.18 \%$ & 52.42 & 0.64 & 650 & & 1 \\
\hline 28 & 40.17919 & 25.23 & 44.71 & $4.25 \%$ & 56.04 & 0.69 & 650 & & 2 \\
\hline 29 & 39.56500 & 25.29 & 44.67 & $5.63 \%$ & 56.06 & 0.69 & 650 & Density & 1 \\
\hline 30 & 40.10592 & 25.25 & 44.68 & $4.36 \%$ & 61.19 & 0.75 & 650 & $\left(\mathrm{~g} / \mathrm{mm}^{3}\right):$ & 1 \\
\hline 31 & 42.23273 & 25.430 & 44.822 & $0.00 \%$ & 84.22 & 1.03 & & 0.0018552 & 2 \\
\hline 32 & 42.14143 & 25.407 & 44.850 & $0.00 \%$ & 76.92 & 0.94 & & 0.0018533 & 3 \\
\hline 33 & 42.15136 & 25.469 & 44.568 & $0.00 \%$ & 84.99 & 1.04 & & 0.0018564 & 3 \\
\hline 34 & 42.01182 & 25.416 & 44.869 & $0.00 \%$ & 81.87 & 1.00 & & 0.0018456 & 2 \\
\hline 35 & 42.09039 & 25.417 & 44.820 & $0.00 \%$ & 79.51 & 0.98 & & 0.0018509 & 1 \\
\hline
\end{tabular}

The fracture column captures how the specimens failed during compression testing. This methodology is used qualitatively to determine whether the specimen fails in an expected manner and whether failure trends may be attributed to oxidation behavior. Failure behavior is designated into one of four categories, with the fourth category indicating a non-specific, general failure behavior. The four categories are defined as follows: 
Category 1. Fracture initiates at the surface of the long axis from tensile forces as the outer material surfaces are strained, resulting in the loss of a wedge-shaped component from the specimen side. Ends often remain intact, and specimen may or may not be completely severed. This is known as a beltline fracture.

Category 2. Shear fracture with the major failure surface lying 55-65 degrees from the specimen ends. Fractures that fit this description but do not lie between 55 and 65 degrees should be listed under Category 4, with the failure angle estimated to the nearest 5 degrees.

Category 3. Fracture surface has a large portion lying parallel to the applied force (long axis direction). It will also regularly contain a shear-fracture component, but the cleavage surface contains at least $50 \%$ of the overall specimen height. This is known as a cleavage fracture.

Category 4. Any fracture condition not described by the other categories (i.e., specimen brittle fracture that leaves few major portions that can be classified) or a shear fracture that does not lie between $55^{\circ}$ and $65^{\circ}$.

Examples of each fracture category are seen below in Figure 8.
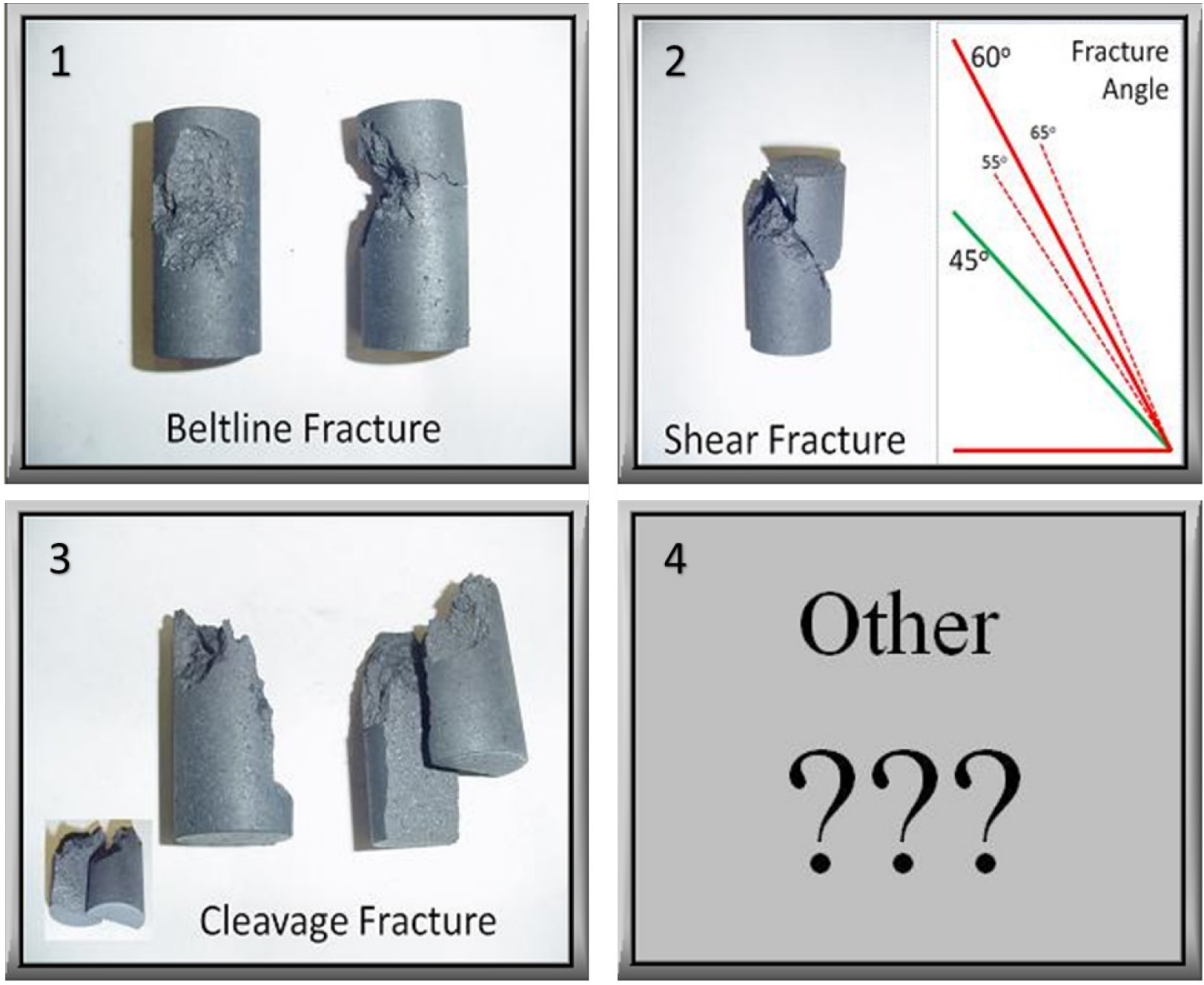

Figure 9. Examples of fracture behavior categories. 


\subsection{Image Analysis}

The radial porosity profiles generated after oxidation for a sample of each grade at each oxidation temperature are shown in Figure 9 and Figure 10. As discussed previously, the low-temperature oxidation is expected to be uniform, kinetically controlled oxidation providing a low reaction rate and, thus, a high penetration depth into the graphite microstructure. High-temperature diffusion-controlled oxidation provides a high reaction rate where the outer layers of graphite are oxidized rapidly, and only limited penetration into the microstructure is possible. This oxidation behavior has been described as the shrinking-core model.

It can be seen that $550^{\circ} \mathrm{C}$ oxidation demonstrates fairly uniform porosity, with no real visible line of penetration depth, verifying uniform oxidation throughout the entire graphite microstructure. Conversely, the $750^{\circ} \mathrm{C}$ oxidation demonstrates a very small penetration-depth profile with minimal oxidation occurring in the center of the samples, verifying the rapid diffusion controlled oxidation. The $650^{\circ} \mathrm{C}$ middle temperature demonstrates an intermediate behavior, having a gradual porosity profile, but also a significant damaged layer near the surface of the samples. The image analysis results align closely with expectations and allow for better interpretation of the mechanical testing results. 

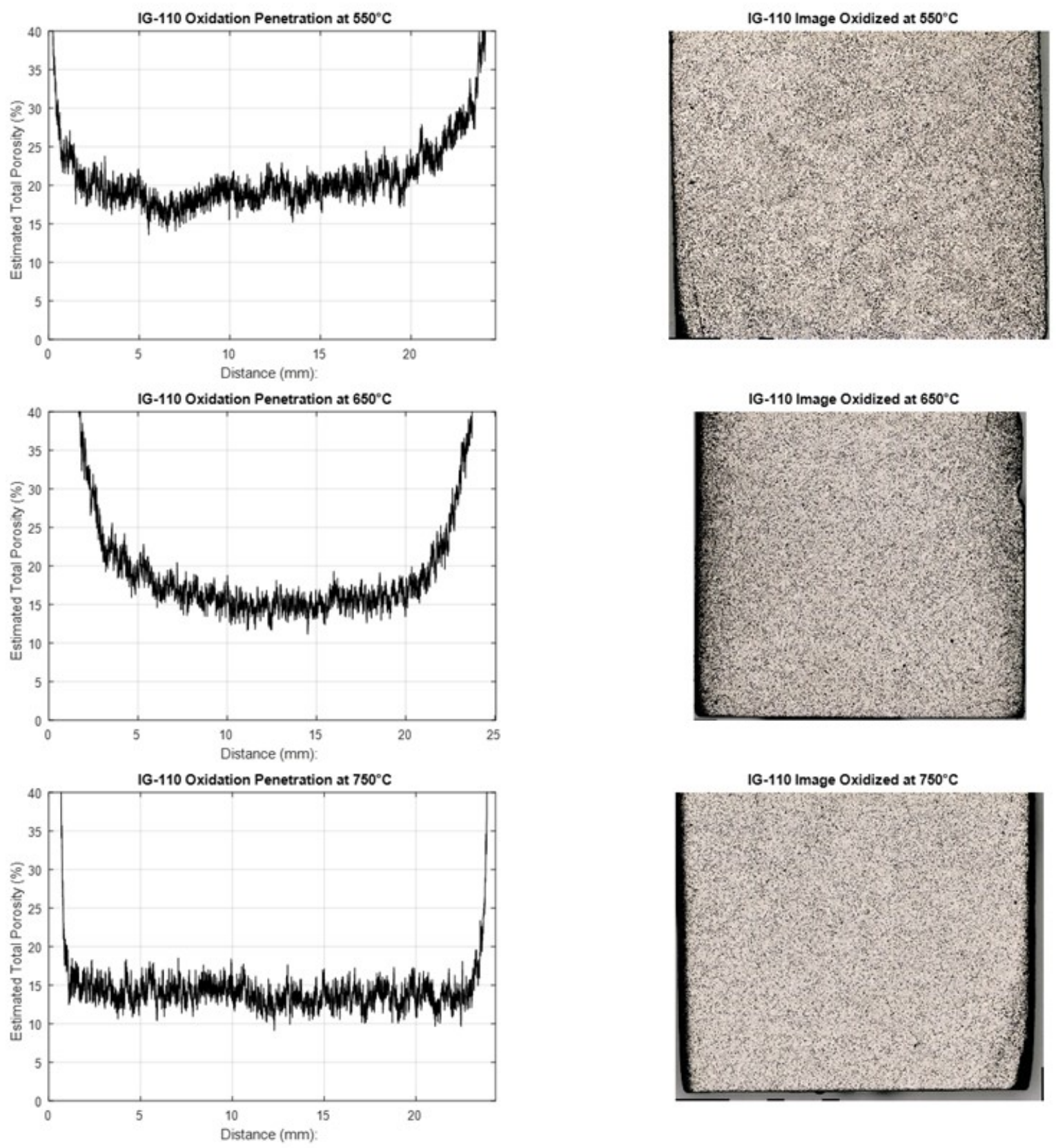

Figure 10. Radial porosity profiles for IG-110 at various temperatures. 

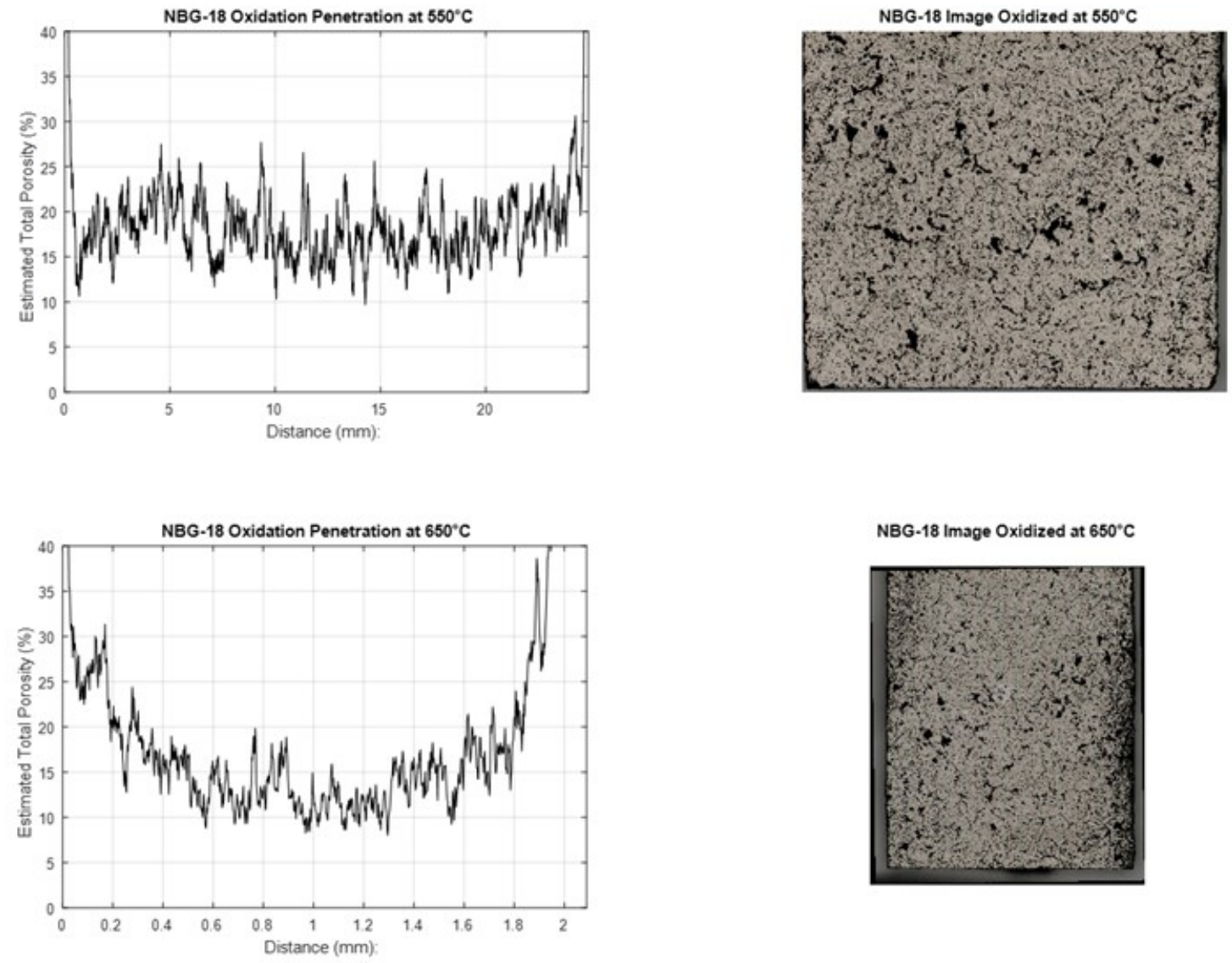

NBG-18 Image Oxidized at $650^{\circ} \mathrm{C}$
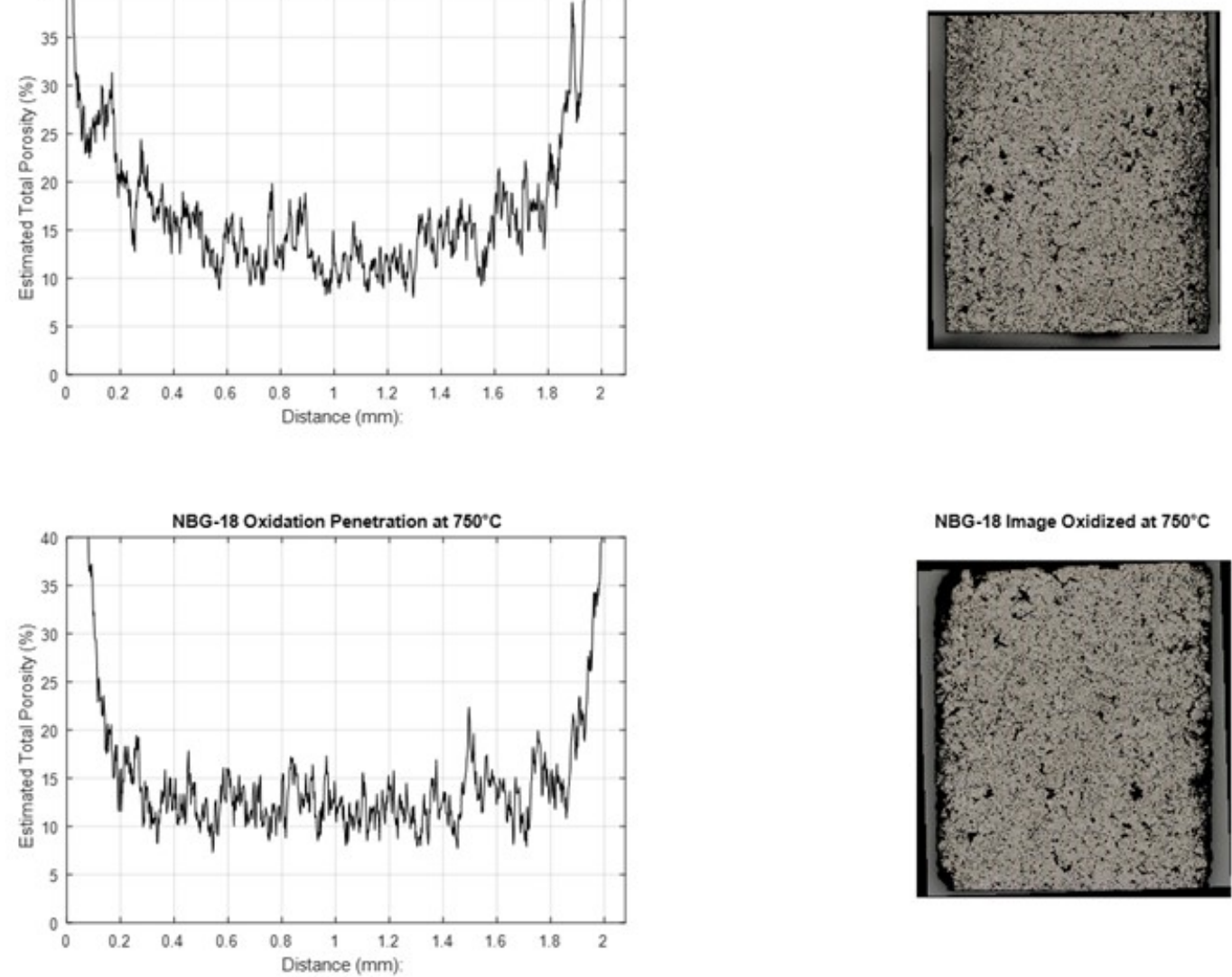

NBG-18 Image Oxidized at $750^{\circ} \mathrm{C}$

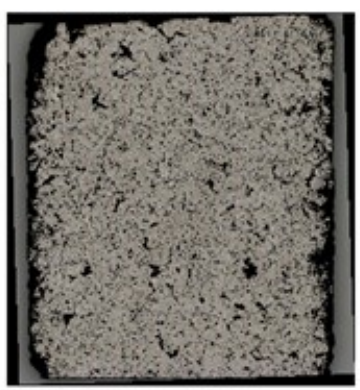

Figure 11. Radial porosity profiles for NBG-18 at various temperatures. 


\section{DISCUSSION}

The graphite oxidation and post-oxidation mechanical data are herein discussed. These results are compared to the observations from optical image analysis for all oxidation temperatures tested.

\subsection{Trends in Strength vs Oxidation Data}

As expected, mechanical strength decreased with oxidation of graphite specimens at all temperatures. However, many previous studies have largely ignored or found no effect of oxidation temperature on graphite strength $[26,27,28,29,30]$, leaving a need for understanding the effect of oxidation temperature on failure stress. As seen in Figure 7, several interesting mechanical behaviors are noted; the $750^{\circ} \mathrm{C}$ conditions have the highest retained failure stress. The decrease in failure stress from $5 \%$ to $10 \%$ mass loss at a given temperature is very similar between grades with the exception of the $650^{\circ} \mathrm{C}$ condition. The trends between graphite grades are very different.

\subsubsection{Effects of High- and Low-temperature Oxidation}

From Figure 7, generally all specimens oxidized at the highest temperature $\left(750^{\circ} \mathrm{C}\right)$, and the most aggressive oxidation condition, yield higher failure stress values than specimens oxidized at the lower temperatures. Only NBG-18 specimens oxidized at $550^{\circ} \mathrm{C}$ to $3-4 \%$ mass loss display similar strength levels, but the strength reduces rapidly as the mass loss increases, so that by $10 \%$ mass loss, the $550^{\circ} \mathrm{C}$ oxidized specimens are considerably weaker than the specimens oxidized at $750^{\circ} \mathrm{C}$. This is explained by the oxidation behavior. At $750^{\circ} \mathrm{C}$ the reaction between carbon and oxygen is much faster than the rate of transport of oxygen into the graphite microstructure, resulting in oxidation occurring primarily in a thin layer near the surface, leaving the bulk of the graphite relatively intact. This results in an effective shrinking of the sample, with little internal damage. Note, the thin oxidized layer on the surface of the graphite still reduces specimen-diameter dimensions, resulting in an overall loss of mechanical strength, as observed. Additionally, optical analysis observed the development of surface irregularities, which may result in stress-concentration points, leading to regions of high stress as well as a small amount of oxygen still penetrating into the graphite microstructure and causing some internal damage.[10,31]

The converse is observed for the low-temperature oxidized specimens, which demonstrate lower strength values for all specimens, again except for NBG-18 specimens oxidized at $550^{\circ} \mathrm{C}$. At $550^{\circ} \mathrm{C}$, the reaction between carbon and oxygen is much slower than the rate of transport of oxygen into the graphite microstructure, resulting in the majority of the oxidation occurring within the interior of the specimen. Thus, while the outer surface of the specimens remains relatively intact (unlike the specimens oxidized at $750^{\circ} \mathrm{C}$ ), the entire interior microstructure of the specimen has been damaged by oxidation. This internal oxidation damage throughout the entire specimen results in much lower failure stress levels than is generally observed for the higher-temperature oxidation conditions.

The high-temperature oxidation occurs in the diffusion-limited regime, where the samples are effectively shrinking with little internal damage. Low-temperature oxidation occurs in the kinetically controlled regime, where the oxidation is close to uniform throughout the sample.[10] However, oxidation at $650^{\circ} \mathrm{C}$ is within the transition-temperature regime (between mostly diffusion-controlled and kineticcontrolled oxidation). It is observed that different grades oxidized within this transition regime will react differently, depending upon the specimen's microstructure. Because oxidation behavior is microstructure dependent, the oxidation behavior for each grade at these intermediate temperatures can vary, with one exhibiting more diffusion-controlled behavior and another showing more kinetic-controlled behavior. Thus, the oxidation regimes causing different penetration depths, different porosity gradients, and different failure stress are dependent upon the unique graphite-grade microstructure. This explains the different failure stress results seen in Figure 7 for the NBG-18 specimens oxidized at $650^{\circ} \mathrm{C}$. Mechanical test results for $650^{\circ} \mathrm{C}$ NBG- 18 specimen are closer to the behavior observed for high temperature $\left(750^{\circ} \mathrm{C}\right)$ 
specimens; i.e., they exhibit a diffusion-controlled behavior, quite different from the $650^{\circ} \mathrm{C}$ oxidized IG-110, which clearly shows results closer to the kinetic-controlled results of the $550^{\circ} \mathrm{C}$ oxidized IG-110 specimens.

\subsubsection{Differences Between Grades}

It is seen both in the strength values in Figure 7 and oxidation profile plots in Figure 9 and Figure 10, that oxidation occurs much differently between the two grades. This is most easily observed under the $650^{\circ} \mathrm{C}$ conditions. The difference in tested strength values can be attributed to the difference in oxygen penetration depth within the microstructure. Many factors affect oxygen penetration including sample size, geometry, and of course microstructure.[10] Characteristic concentration profiles for oxygen in graphite for various temperatures can be seen below in Figure 11.

The microstructural difference between grades is the largest factor in oxidation behavior. From previous oxidation studies, IG-110 has demonstrated a much higher effective diffusion coefficient than NBG-18,[17] which means oxygen can more easily penetrate the graphite. NBG-18 has a higher overall density, larger grain size, and a lower open-pore density than IG-110, which may significantly affect the differences between oxidation-penetration depths at a given temperature.[9] Together, these microstructural differences can be attributed to the difference in oxidation profile and the resultant difference in failure-load decrease between the two grades.

$\begin{array}{c:cc}\text { Reaction occurs at the exterior sur- } & \text { Most reported kinetics data for nu- } & \text { Characterized by low observed } \\ \text { face and rate changes with shrink- } & \text { clear graphite occurs within } & \text { rates at "low" temperatures. Oxi- } \\ \text { ing geometric surface area. The } & \text { Regime 2. The observed activation } & \text { dation occurs uniformly within } \\ \text { effective reaction rate is orders of } & \text { is roughly half the effective activa- } & \text { open pore structure. Mass trans- } \\ \text { magnitude faster than gas diffu- } & \text { tion energy at the same tempera- } & \text { port is orders of magnitude faster } \\ \text { sion. The observed activation } & \text { ture. Oxidation is non-uniform and } & \text { than observed reaction rate. Under } \\ \text { energy is } \sim 10 \mathrm{~kJ} / \mathrm{mol} \text { or less. } & \text { may not fully penetrate into the } & \text { most lab scale testing of nuclear } \\ \text { Regime } 3 \text { is rapidly approaching } & \text { open pore structure. } & \text { graphite, Regime } 1 \text { can not be ob- } \\ \text { by } 800^{\circ} \mathrm{C} \text {. } & & \text { tained above } 550^{\circ} \mathrm{C} \text {. }\end{array}$

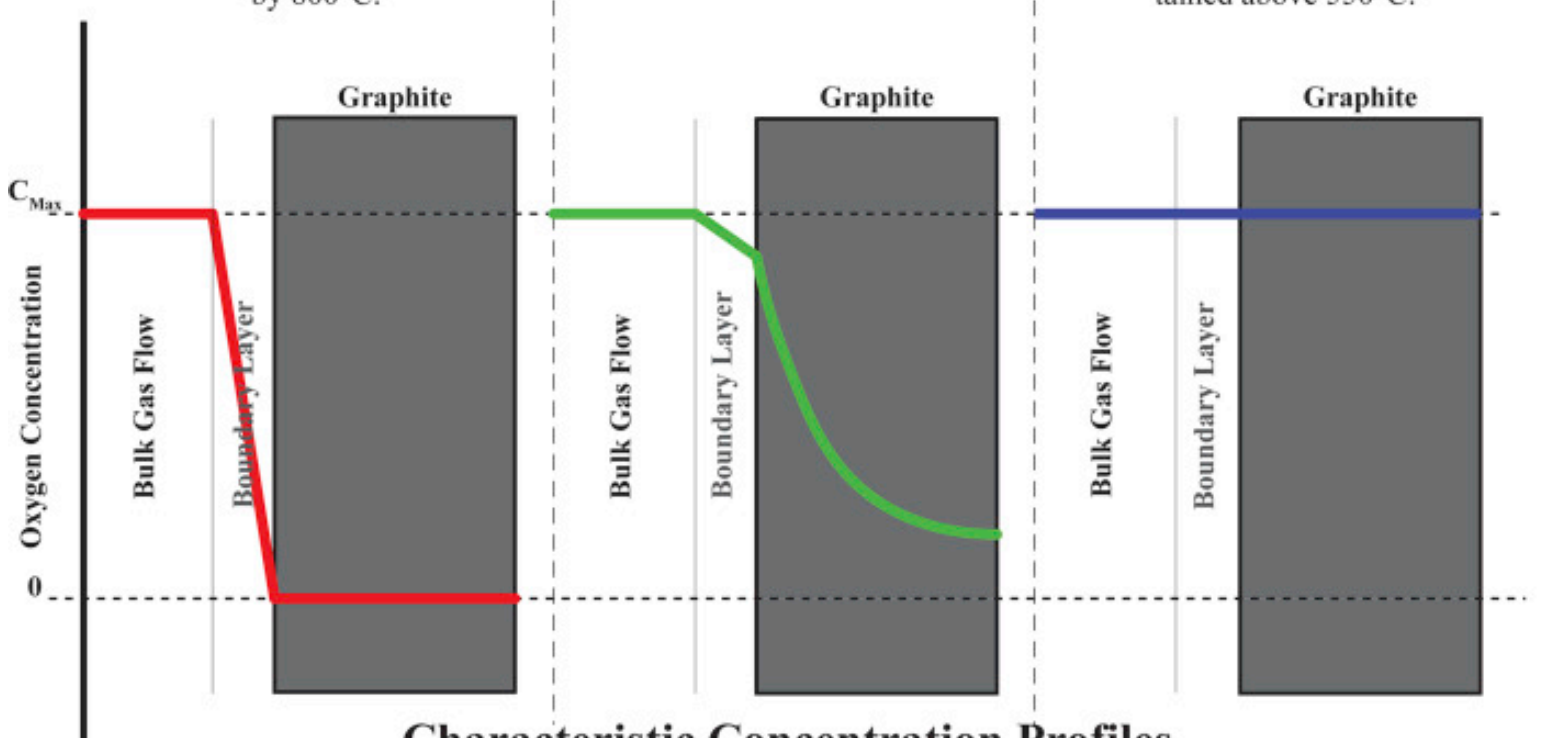

Characteristic Concentration Profiles

*While temperature is a substantial factor in determining the regime experimental data may fall within, other factors include sample size, geometry, gas flow rate, and microstructure.

**The ideal Regimes 1 and 3 depicted in the characteristic concentration profiles can be thought of as the upper and lower bounds of the Thiele modulus. In reality all experimental data lies somewhere between these two extremes.

Figure 12. Characteristic oxygen concentration profiles for graphite at different temperatures.[10] 


\subsection{Application of Results}

While the results from this work are geometry dependent, and not directly scalable to larger components, they nevertheless contain vital information for reactor designers. This study clearly demonstrates that residual strength of graphite after oxidation does not depend solely on mass loss, but also on oxidation temperature and oxidant availability. Figure 7 shows that at $10 \%$ mass loss, a graphite grade can lose $15-50 \%$ (or more) of its as-fabricated strength, depending on the temperature to which it is exposed during oxidation.

Current ASME code assumes zero strength at 10\% mass loss, regardless of oxidation temperature.[7] Clearly, this is too conservative and should be addressed within the ASME code-development activities. This conclusion is especially valid with respect to the large components expected to be used within a new HTR core design. ASME code must address the penetration depth and variable strength issues that have been raised within this study. Finally, this study illustrates that further work is also necessary in calculating where the oxidation actually occurs within an HTR core. As stated, the current 2017 ASME code directs that any component suffering from a maximum of $10 \%$ mass loss must be considered to have no mechanical strength. However, no guidance on how the mass loss should be achieved is provided. Because this work shows that the oxidation temperature is critical to determining residual strength within oxidized components, consideration as to where the oxidation might occur must be addressed. For example, if oxidation only occurs within the hottest region of the core, and the oxidation is assumed to be diffusion-controlled, then the structural integrity of the core components will be calculated differently from components suffering oxidation at lower temperatures outside of this central hot core zone. 


\section{CONCLUSIONS}

Several interesting results have been observed with this study both in oxidation behavior and the effects on mechanical strength. Differences attributed to oxidation temperature, graphite microstructures, and pore microstructures. The major conclusions are summarized as:

1. The mechanical strength decreased with oxidation of the graphite specimens at all temperatures.

2. However, the strength changes tended to vary due to oxidation temperature. The general trends noted for oxidation temperature variations are:

a. Specimens oxidized at the highest temperature $\left(750^{\circ} \mathrm{C}\right)$ and most aggressive oxidation condition yield higher failure-stress values than specimens oxidized to similar mass loss levels at lower temperatures.

b. Specimens oxidized at the lowest temperature $\left(550^{\circ} \mathrm{C}\right)$ demonstrated lower strength values than specimens oxidized to similar mass-loss levels at the highest temperatures.

c. Specimens oxidized at $650^{\circ} \mathrm{C}$ showed a mixed behavior, with the medium-grained grade (NBG-18) showing lower failure-stress values than their counterpart $550^{\circ} \mathrm{C}$ specimens and the fine-grained grade (IG-110) demonstrating higher strength values than did $550^{\circ} \mathrm{C}$ specimens.

d. It was assumed that this difference occurs because $650^{\circ} \mathrm{C}$ conditions are within the transitiontemperature regime and the oxidation behavior is extremely dependent upon the unique microstructures expected from each grade.

e. Depending upon the microstructure the oxidation behavior can behave more like hightemperature (i.e., diffusion-controlled) or low-temperature (kinetic-controlled) oxidation.

3. Oxidation and strength changes behave differently between the two grades. As explained in the $650^{\circ} \mathrm{C}$ oxidation conditions, this is attributed to the difference in oxygen-penetration depth within the unique graphite microstructure.

4. Optical-image results inform and confirm the influence that unique graphite microstructure has on the effects of oxidation.

a. From optical image analysis of oxidized specimens, it can be seen that the $550^{\circ} \mathrm{C}$ oxidation demonstrates fairly uniform porosity, with no visible line of penetration depth, verifying uniform oxidation throughout the entire graphite microstructure.

b. Conversely, the $750^{\circ} \mathrm{C}$ oxidation demonstrates a very small penetration-depth profile, with minimal oxidation occurring in the center of the samples, verifying the rapid diffusion-controlled oxidation.

c. The $650^{\circ} \mathrm{C}$ middle temperature demonstrates an intermediate behavior, having a gradual porosity profile but also a significantly damaged layer near the surface of the samples.

5. Current ASME code assumes zero strength at $10 \%$ mass loss regardless of oxidation temperature. Clearly, this is too conservative and should be addressed within the ASME code development activities. 


\section{REFERENCES}

[1] T. Burchell, R. Bratton, and W. Windes, "NGNP Graphite Selection and Acquisition Strategy," Oak RIdge National Laboratory, 2007.

[2] Burchell, R. L. Bratton and T. D., "NGNP Graphite Testing and Qualification Specimen Selection Strategy," Idaho National Laboratory, 2005.

[3] “PLN-2497, 2010, “Graphite Technology Development Plan”," Idaho National Laboratory, 2010.

[4] Harvego, E.A. \& Reza, S.M.M. \& Richards, Matt \& Shenoy, A., "An evaluation of reactor cooling and coupled hydrogen production processes using the modular helium reactor," Nuclear Engineering and Design, vol. 236, pp. 1481-1489, 2006.

[5] Geschwindt, J \& Lommers, Lewis \& H. Southworth, F \& Shahrokhi, Farshid, "Performance and optimization of an HTR cogeneration system," Nuclear Engineering and Design, vol. 251, 2012.

[6] M. W. Patterson, "Cogeneration of electricity and liquid fuels using a high temperature gas-cooled reactor as the heat source," Nuclear Engineering and Design, vol. 329, pp. 204-212, 2018.

[7] American Society of Mechanical Engineers, 2017 ASME Boiler \& Pressure Vessel Code: An International Code, Section III: Rules for Construction of Nuclear Facility Components, Division 5: High Temperature Reactors, New York, NY: ASME, 2017.

[8] Contescu, Cristian \& R Guldan, Tyler \& Wang, Peng \& Burchell, Timothy, "Effect of microstructure on air oxidation resistance of nuclear graphite," Carbon, vol. 50, pp. 3354-3366, 2012.

[9] Se-Hwan Chi, Gen-Chan Kim, "Comparison of the oxidation rate and degree of graphitization of selected IG and NBG nuclear graphite grades," Journal of Nuclear Materials Volume 381, pp. 9$14,2008$.

[10] J.J. Kane, C.I. Contescu, R.E. Smith, G. Strydom, W.E. Windes, "Understanding the reaction of nuclear graphite with molecular oxygen: kinetics, transport, and structural evolution," J. Nucl. Mater 493, pp. 343-367, 2017.

[11] Kyotani, Takashi, Carlos A. Leon Y Leon, and Ljubisa R. Radovic, "Simulation of carbon gasification kinetics using an edge recession model," AIChE journal, vol. 39, no. 7, pp. 1178-1185, 1993.

[12] NR Laine, FJ Vastola, PL Walker Jr., "The importance of active surface area in the carbon-oxygen reaction1, 2," The Journal of physical chemistry, vol. 67, no. 10, pp. 2030-2034, 1963.

[13] Lizzio, Anthony A., Hong Jiang, and Ljubisa R. Radovic, "On the kinetics of carbon (char) gasification: reconciling models with experiments," Carbon, vol. 28, no. 1, pp. 7-19, 1990.

[14] Choi, E. Y., San Choi, W., Lee, Y. B., \& Noh, Y. Y., "Production of graphene by exfoliation of graphite in a volatile organic solvent," Nanotechnology, vol. 22, no. 36, 2011.

[15] El-Genk, Mohamed S., and Jean-Michel P. Tournier, "Development and validation of a model for the chemical kinetics of graphite oxidation," Journal of Nuclear Materials, vol. 411, no. 1-3, pp. 193-207, 2011.

[16] El-Genk, Mohamed S., and Jean-Michel P. Tournier, "Validation of gasification model for NBG18 nuclear graphite," Nuclear Engineering and Design, vol. 250, pp. 142-155, 2012. 
[17] Joshua J. Kane, Austin C. Matthews, Christopher J. Orme, Cristian I. Contescu, W. David Swank, William E. Windes., "Effective gaseous diffusion coefficients of select ultra-fine, super-fine and medium grain nuclear graphite," Carbon Volume 136, pp. 369-379, 2018.

[18] P.L. Walker Jr., Frank Rusinko Jr., L.G. Austin, “Gas Reactions of Carbon,” Advances in Catalysis, vol. 11, pp. 133-221, 1959.

[19] Contescu, C. I., Azad, S., Miller, D., Lance, M. J., Baker, F. S., \& Burchell, T. D., "Practical aspects for characterizing air oxidation of graphite," Journal of nuclear materials, vol. 381, no. 1-2, pp. 15-24, 2008.

[20] Wichner, R. P., Burchell, T. D., \& Contescu, C. I., "Penetration depth and transient oxidation of graphite by oxygen and water vapor," Journal of Nuclear Materials, vol. 393, no. 3, pp. 518-521, 2009.

[21] ASTM, “ASTM D7219, Standard Specification for Isotropic and Near-isotropic Nuclear Graphites".

[22] B. T. Kelly, "Physics of Graphite," Applied Sciences Publishers LTD, London, 1981.

[23] R. E. Nightingale, Nuclear Graphite, Academic Press, ISBN: 978-1-4832-2854-9, 1962.

[24] ASTM, "C695-15 Standard Test Method for Compressive Strength of Carbon and Graphite," 2015.

[25] Xiangwen Zhou, Cristian I. Contescu, Xi Zhao, et al., "Oxidation Behavior of Matrix Graphite and Its Effect on Compressive Strength," Science and Technology of Nuclear Installations, p. 6 pages, 2017.

[26] R. J. Price, L.A. Beavan, "Strength of Nonuniformly Oxidized PGX Graphite," General Atomic Co., San Diego, 1981.

[27] A.C. Collins, H.G. Masterson, P.P. Jennings. "The effect of oxidation on the compressive strength of graphite," Journal of Nuclear Materials, vol. 15, no. 2, pp. 135-136, 1965.

[28] T. Peng, "Effects of Oxidation on the Mechanical Properties of Carbon/Graphite," in Carbon, Irvine, CA, 1977.

[29] T. Peng, "Oxidation effects on the tensile strength of ATJS graphite and vitreous carbon," Carbon, vol. 17, no. 2, pp. 157-174, 1979.

[30] M. Eto, F.B. Growcock, "Effect of oxidizing environment on the strength of H451, PGX and IG11 graphites," Carbon, vol. 21, no. 2, pp. 135-147, 1983.

[31] Uo Xiaowei, Robin Jean-Charles, Yu Suyuan, "Effect of temperature on graphite oxidation behavior," Nuclear Engineering and Design, vol. 227, no. 3, pp. 273-280, 2004. 